\title{
SATB1 protein is associated with the epithelial-mesenchymal transition process in non-small cell lung cancers
}

\author{
NATALIA GLATZEL-PLUCINSKA ${ }^{1}$, ALEKSANDRA PIOTROWSKA ${ }^{1}$, ADAM RZECHONEK ${ }^{2}$, \\ MARZENNA PODHORSKA-OKOLOW ${ }^{3}$ and PIOTR DZIEGIEL ${ }^{1,4}$
}

\begin{abstract}
${ }^{1}$ Division of Histology and Embryology, Department of Human Morphology and Embryology, Wroclaw Medical University, 50-368 Wroclaw; ${ }^{2}$ Department of Thoracic Surgery, Wroclaw Medical University, 53-439 Wroclaw;

${ }^{3}$ Department of Ultrastructural Research, Wroclaw Medical University, 50-368 Wroclaw; ${ }^{4}$ Department of Physiotherapy, Wroclaw University School of Physical Education, 51-612 Wroclaw, Poland
\end{abstract}

Received December 9, 2020; Accepted February 25, 2021

DOI: $10.3892 /$ or.2021.8069

\begin{abstract}
Lung cancer is one of the most frequently diagnosed neoplasms and the leading cause of cancer-related mortality worldwide. Its predominant subtype is non-small cell lung cancer (NSCLC), which accounts for over $80 \%$ of the cases. Surprisingly, the majority of lung cancer-related deaths are caused not by a primary tumour itself, but by its metastasis to distant organs. Therefore, it becomes especially important to identify the factors involved in lung cancer metastatic spread. Special AT-rich binding protein 1 (SATB1) is a nuclear matrix protein that mediates chromatin looping and plays the role of global transcriptional regulator. During the past decade, it has received much attention as a factor promoting tumour invasion. In breast, colorectal and prostate cancers, SATB1 has been shown to influence the epithelial-mesenchymal transition (EMT) process, which is thought to be crucial for cancer metastasis. The aim of this study was to analyse the possible correlations between the expression of SATB1 and major EMT-associated proteins in NSCLC clinical samples. Additionally, the impact of EMT induction in NSCLC cell lines on SATB1 mRNA expression was also investigated. Immunohistochemistry was used to assess the expression of SATB1, SNAIL, SLUG, Twist1, E-cadherin, and N-cadherin in 242 lung cancer clinical samples. EMT was induced by TGF- $\beta 1$ treatment in the A549 and NCI-H1703 lung cancer cell lines. Changes in gene expression profiles were analyzed using real-time PCR and Droplet Digital PCR. SATB1
\end{abstract}

Correspondence to: Mrs. Natalia Glatzel-Plucinska, Division of Histology and Embryology, Department of Human Morphology and Embryology, Wroclaw Medical University, Chałubińskiego 6a, 50-368 Wroclaw, Poland

E-mail: natalia.glatzel-plucinska@umed.wroc.pl

Key words: SATB1, special AT-rich binding protein 1, NSCLC, adenocarcinoma, LSCC, EMT, non-small cell lung carcinoma, lung adenocarcinoma, lung squamous cell carcinoma, epithelial-mesenchymal transition, metastasis expression was positively correlated with the expression of SNAIL ( $\mathrm{R}=0.129 ; \mathrm{P}=0.045)$, SLUG $(\mathrm{R}=0.449 ; \mathrm{P}<0.0001)$, and Twist1 ( $\mathrm{R}=0.264 ; \mathrm{P}<0.0001)$. Moreover, SATB1 expression significantly increased after in vitro EMT induction in A549 and NCI-H1703 cell lines. The results obtained may point to the role of SATB1 as one of the regulators of EMT in NSCLC.

\section{Introduction}

With more than 2 million new cases and 1.8 million deaths every year, lung cancer is one of the most frequently diagnosed neoplasms and the leading cause of cancer-related mortality worldwide (1). Unfortunately, despite the development of new forms of treatment, over half of lung cancer patients die within one year of the diagnosis, and the 5-year survival rates do not exceed $18 \%$ (2). The predominant lung cancer subtype is non-small cell lung cancer (NSCLC), which accounts for over $80 \%$ of cases (3). NSCLCs are highly heterogeneous and have diverse pathological features, thus further histological subtypes are usually distinguished. The most common ones are adenocarcinoma (AC) and squamous cell carcinoma (LSCC) (3).

It is estimated that $90 \%$ of NSCLC-related deaths are caused not by the primary tumour itself, but by its metastases to distant organs (4). For lung cancers, the preferable sites for metastasis are the bones, the lungs, the brain, the adrenal glands and the liver, but the exact patterns of metastatic spread are highly dependent on the histological and molecular subtype of the tumour (5-7). Nevertheless, the presence of distant metastases is an unequivocal hallmark of poor prognosis; for patients with localized NSCLC tumours, the 5-year relative survival rate is approximately $60 \%$, while for disseminated cancers, it decreases 10 -fold to only $6 \%$ (data from the USA) (8).

The metastasis mechanism, although very complex and not fully understood yet, is commonly thought to rely on two main processes: The epithelial-to-mesenchymal and the mesenchymal-to-epithelial transitions (EMT and MET, respectively). The activation of EMT-promoting traits supports tumour cell invasion and dissemination, while the reverse process, MET, is believed to promote metastatic outgrowth once cancer cells have extravasated and invaded the distant 
organs (9). During EMT, epithelial cells lose their apical-basal polarity, cell-to-cell junctions and interactions, and contact with the basal membrane (9-12). They significantly change their morphology and become elongated and spindle-shaped, slowly gaining migration and invasion abilities (9-12). The expression of key epithelial markers such as E-cadherin or cell junction proteins gradually decreases and the cells start to express proteins typical for the mesenchymal phenotype: $\mathrm{N}$-cadherin, vimentin, and matrix metalloproteinases (MMPs) (9-11). Physiologically, EMT has been shown to be essential for embryonic development, organogenesis, and tissue repair (12). However, in pathological conditions, as a result of EMT, cancer cells can acquire key metastatic features, including enhanced mobility, invasion ability, and resistance to apoptosis, enabling them to infiltrate the surrounding stroma and to spread through the blood and lymphatic vessels to distant sites (9). In epithelial tumours, EMT is usually chaotic and incomplete, and there are coexisting cells in numerous intermediate states, presenting features of both epithelial and mesenchymal phenotypes $(13,14)$. EMT has long been defined by the loss of the expression of the epithelial marker E-cadherin and the acquisition of the expression of mesenchymal markers vimentin and/or N-cadherin (15). Nowadays, it is known that in cancer cells, EMT is not a binary process, and both epithelial and mesenchymal markers are often co-expressed (15).

The transition from epithelial to mesenchymal phenotype is orchestrated by numerous transcription factors, the most important of which are SNAIL, SLUG,ZEB1,ZEB2, and Twist1 proteins (9-11). Additionally, it is also regulated epigenetically and at a post-transcriptional level by a variety of different factors, including chromatin modifying enzymes, miRNAs, and long non-coding RNAs (11). Although the relationship between the loss of E-cadherin expression and the increased invasiveness of cancer cells was described for the first time about 30 years ago (16) and the link between EMT and cancer metastasis has been known for almost 20 years (17), the exact molecular pathways associated with EMT in lung cancers and their clinical implications have not yet been fully studied. It has been demonstrated that cigarette smoking, which is considered to be a direct cause of $85-90 \%$ of lung cancer cases, can clearly contribute to EMT by decreasing E-cadherin expression (18). It has also been shown that smoking increases the activity of SNAIL and Twist1 in the basal cells of the respiratory epithelium (19). The importance of EMT in NSCLC goes far beyond increasing the metastatic potential and invasiveness of tumour cells. The shift towards a mesenchymal phenotype in these tumours has been linked to the acquired resistance to epidermal growth factor receptor (EGFR) inhibitors, which are the first-line treatment for NSCLC patients harbouring activating EGFR mutations (20-22). Interestingly, treatment with EGFR inhibitors was also revealed to be one of the EMT-promoting factors (23). Moreover, as in the case of other cancers, in lung carcinomas, EMT was found to be a strong factor contributing to chemoresistance and radioresistance (24-27). Therefore, it becomes especially important to identify and investigate additional factors that might potentially contribute to EMT in NSCLC.

During the past decade, SATB1 (special AT-rich binding protein 1) has received much attention as a factor promoting tumour invasion and metastasis. SATB1 is a nuclear matrix protein that mediates chromatin looping and plays the role of a global transcriptional regulator $(28,29)$. It binds to base-unpairing regions (BURs), the specific AT-rich motifs of double-stranded DNA that may be found every 40,000 DNA base pairs (28-30). The binding of SATB1 to BURs provides a nuclear platform necessary for the binding of further transcription factors and chromatin-modifying enzymes, regulates epigenomic modifications and maintains proper nucleosome positioning (30). It binds to distinct genomic regions depending on the cell type. Therefore, it has the ability to regulate whole sets of genes in a tissue-specific manner $(28,29,31)$. SATB1 interactions with transcription activators and repressors are determined by post-transcriptional modifications such as phosphorylation or acetylation $(32,33)$. SATB1 can also be regulated by numerous microRNAs (34-40).

Physiologically, SATB1 is expressed in embryonic stem cells and in many adult progenitor cells, for example ameloblasts and osteoblasts $(30,41,42)$. It is essential for embryonic development, and it takes part in processes that require rapid changes in the cell phenotype, such as the differentiation and maturation of thymocytes or skin epithelial cells $(28,30)$. Besides its normal physiological function, SATB1 was also found to be overexpressed in numerous malignancies, including breast, colorectal, prostate, liver, bladder, and ovarian cancers (43-49). In these tumours, a high SATB1 level was clearly associated with an aggressive phenotype, the presence of metastasis and a poor patient prognosis (43-49).

In most of the abovementioned cancers, a high SATB1 level was also shown to influence the EMT process and to impact the expression of EMT-related proteins. In breast cancer cells, SATB1 was found to promote the mesenchymal phenotype by upregulating vimentin and $\mathrm{N}$-cadherin, as well as downregulating the key epidermal markers claudin-1, $\beta$-catenin, and E-cadherin (43). It also stimulated the expression of the most crucial EMT-associated transcription factors: SNAIL and Twist1 (50). It was shown to play a role in the induction of chemotherapy-related EMT (36), and to increase the number of breast cancer stem cells (BCSCs) within the tumours (50). Moreover, SATB1 depletion in MDA-MB-231, a highly aggressive and tumorigenic breast cancer cell line, was demonstrated to reverse the EMT process and to significantly change the phenotype of the cells, restoring their polarization and acinar-like morphology (43). In colorectal tumours, SATB1 expression was found to be positively correlated with the expression of vimentin, and negatively with the expression of the epithelial proteins E-cadherin and CK20 (51). SATB1 knockdown in colorectal cancer cell lines was shown to affect the expression of EMT-related proteins, including E-cadherin, N-cadherin, SLUG, and Twist1 (52). Links between SATB1 expression and the EMT process were also observed in prostate cancer. The studies on the loss-of-function models revealed that SATB1 expression was required to maintain the invasive phenotype of prostate cancer cells, and that its knockdown significantly inhibited cell growth, proliferation, and invasion rates (45,53-55). Moreover, its silencing was shown to increase E-cadherin expression, and to restore the anchorage-dependent growth of the cells together with their polarized morphology $(45,55)$. SATB1 associations with the EMT process have been revealed in liver cancer as well, where SATB1 was shown to 
influence the expression of more than 100 genes related to tumour progression and metastasis, including genes coding for EMT-related proteins such as SNAIL, SLUG, Twist1, vimentin, and E-cadherin (46). Finally, the downregulation of E-cadherin and the upregulation of SNAIL, SLUG, and vimentin as a result of SATB1 overexpression were also observed in bladder cancer cells (56).

Although numerous studies have revealed that SATB1 may have a significant impact on cancer progression, metastasis, and the EMT process, its role in NSCLC remains ambiguous and not fully understood. It is known that SATB1 is necessary for proper lung development during embryogenesis, and that its depletion in mice is lethal (57). It has also been observed that the SATB1 level is elevated in human respiratory epithelial cells $(58,59)$, whereas in the lung alveoli its expression is rather low (59-61). To date, the most comprehensive study concerning the role of SABT1 in NSCLC was published in 2011 by Selinger et al, who were the first to discover that SATB1 expression is associated with lung squamous cell carcinoma (LSCC) tumour histology and a poor degree of histological differentiation in the whole NSCLC study cohort (58). Surprisingly, they also observed that the loss of SATB1 expression was a negative prognostic factor for LSCC patients (58). In 2016, Huang et al assessed SATB1 expression in adenocarcinoma (AC) samples only, and they confirmed that an elevated SATB1 level was related to a higher tumour grade (60). In our recent study, we decided to analyse SATB1 expression in particular NSCLC subtypes separately (59). We found the SATB1 level to be significantly higher in LSCCs in comparison to AC specimens (59), confirming previous findings made by Selinger et al (58). Moreover, while in ACs the expression of SATB1 was associated with a poor degree of histological differentiation, in LSCCs the level of SATB1 was increased in well differentiated tumours (59). We also observed the negative impact of a decreased SATB1 expression on NSCLC patient survival (59). However, the results were statistically significant only for the whole study cohort, and no association was noted between SATB1 expression and the survival of AC patients (59). For LSCC, the results were on the verge of statistical significance (59). These results suggest that in NSCLC, the function of SATB1 may be highly dependent on the exact tumour histology.

There are no reports available on the possible impact of SATB1 expression on the EMT process in NSCLC. Therefore, the aim of this study was to analyse the possible correlations between the expression of SATB1 and major EMT-associated proteins (E-cadherin, N-cadherin, SNAIL, SLUG, and Twist1) in NSCLC clinical samples. Additionally, we also investigated the impact of transforming growth factor (TGF- $\beta 1$ ) exposure, which is commonly used to induce EMT in vitro, on SATBI mRNA expression in AC and LSCC cell lines.

\section{Materials and methods}

Patient cohort. The present study was approved by the Bioethics Commission at the Wroclaw Medical University in Poland (approval no. KB-632/2017). A total of 262 NSCLC and adjacent non-malignant lung tissue (NMLT) samples were collected from patients treated at the Lower Silesian Centre of Lung Diseases in Wroclaw during the years 2007-2016.
The study group consisted of 150 adenocarcinomas (AC), 92 squamous cell carcinomas (LSCC), and 20 non-malignant lung tissue (NMLT) samples. For each sample, formalin-fixed paraffin-embedded (FFPE) tissue blocks were prepared. The histological type of the tumours was assessed using the World Health Organization Classification (3) by two independent pathologists, and was additionally confirmed by immunohistochemical staining for the marker proteins TTF-1 (AC marker) and p63 (LSCC marker). The pTNM classification was made according to the recommendations of the International Association for the Study of Lung Cancer (IASLC) (62). The clinical, pathological, and survival data were obtained from the hospital archives and are listed in Table I.

Cell lines. The NCI-H1703 (LSCC) and A549 (AC) cell lines were obtained from the American Type Culture Collection (ATCC). The cell culture media used were RPMI-1640 (for the NCI-H1703 cell line) and F12K (for the A549 cell line). All of the media were additionally supplemented with L-glutamine up to a final concentration of $2 \mathrm{mM}$, and with fetal bovine serum, up to a final concentration of $10 \%$. All of the cell culture media and reagents were purchased from Sigma-Aldrich; Merck KGaA. Cell culture conditions were as follows: Temperature $37^{\circ} \mathrm{C}$ and $5 \% \mathrm{CO}_{2}$ concentration.

Tissue microarrays (TMAs). Tissue microarrays (TMAs) were created using the TMA Grand Master (3DHistech) automatic tissue microarrayer. From each FFPE tissue block, standard 4- $\mu$ m-thick paraffin sections were cut and hematoxylin and eosin (H\&E) stained. Then, the prepared slides were scanned with a Pannoramic MIDI II (3DHistech) histological scanner. Representative spots for the TMAs (three spots with $1.5 \mathrm{~mm}$ diameter from each FFPE block) were selected by a qualified pathologist from the digital slides with the use of the Case Viewer (3DHistech) software. Finally, TMAs were created using the TMA Grand Master system, according to the manufacturer's instructions.

Immunohistochemistry (IHC). Immunohistochemical reactions were performed on $4-\mu$ m-thick paraffin sections using DAKO Autostainer Link48 (Dako; Agilent Technologies, Inc.). First, deparaffinization, rehydration, and antigen retrieval were performed using EnVision FLEX Target Retrieval Solution ( $\mathrm{pH} \mathrm{9.0,} 20 \mathrm{~min}, 97^{\circ} \mathrm{C}$ ) in PTLink (Dako; Agilent Technologies, Inc.). In order to block the activity of endogenous peroxidase, the sections were incubated in EnVision FLEX Peroxidase-Blocking Reagent (5 min at room temperature). Afterwards, primary antibodies directed against E-cadherin (RTU; cat. no. IR059; Dako; Agilent Technologies, Inc.), N-cadherin (1:50; cat. no. M3613; Dako; Agilent Technologies, Inc.), SNAIL (1:400; cat. no. 13099-1-AP; ProteinTech), SLUG (1:50, cat. no. 166476; SantaCruz Biotechnology, Inc.), and Twist1 (1:500; cat. no. ab50581; Abcam) were applied for $20 \mathrm{~min}$ at room temperature. Then, the slides were incubated with EnVision FLEX/HRP (20 min). Next, 3,3'-diaminobenzidine (DAB, Dako; Agilent Technologies, Inc.) was utilized as the peroxidase substrate, and the sections were incubated for $10 \mathrm{~min}$ at room temperature. Additionally, all the sections were counterstained with FLEX Hematoxylin for $5 \mathrm{~min}$ at room temperature. After dehydration in graded ethanol 
Table I. Clinicopathological data of the NSCLC patients.

\begin{tabular}{|c|c|c|c|}
\hline Parameters & All cases $(\mathrm{N}=242) \mathrm{n}(\%)$ & $\mathrm{AC}(\mathrm{N}=150) \mathrm{n}(\%)$ & $\operatorname{LSCC}(\mathrm{N}=92) \mathrm{n}(\%)$ \\
\hline \multicolumn{4}{|l|}{ Sex } \\
\hline Male & $146(60.3)$ & $85(56.7)$ & $61(66.3)$ \\
\hline Female & $96(39.7)$ & $65(43.3)$ & $31(33.7)$ \\
\hline \multicolumn{4}{|l|}{ Age } \\
\hline Mean & $66.22 \pm 7.65$ & $65.87 \pm 8.14$ & $66.81 \pm 6.77$ \\
\hline Range & $44-84$ & $44-84$ & $44-82$ \\
\hline \multicolumn{4}{|c|}{ Malignancy grade } \\
\hline G1 & $3(1.2)$ & $3(2.0)$ & $0 \quad(0.0)$ \\
\hline $\mathrm{G} 2$ & $152(62.8)$ & $73(48.7)$ & $79(85.9)$ \\
\hline G3 & $87(36.0)$ & $74(49.3)$ & $13(14.1)$ \\
\hline \multicolumn{4}{|l|}{ Tumour size } \\
\hline pT1 & $76(31.4)$ & $56(37.3)$ & $20(21.7)$ \\
\hline pT2 & $124(51.2)$ & $66(44.0)$ & $58(63.0)$ \\
\hline pT3 & $23 \quad(9.5)$ & $11(7.3)$ & $12(13.0)$ \\
\hline pT4 & $5 \quad(2.1)$ & $4 \quad(2.7)$ & $1 \quad(1.1)$ \\
\hline No data & $14 \quad(5.8)$ & $13(8.7)$ & $1 \quad(1.1)$ \\
\hline \multicolumn{4}{|c|}{ Lymph nodes } \\
\hline pNO & $147(60.7)$ & $83(55.3)$ & $64(69.6)$ \\
\hline $\mathrm{pN} 1$ & $40(16.5)$ & $23(15.3)$ & $17(18.5)$ \\
\hline $\mathrm{pN} 2$ & $41(16.9)$ & $31(20.7)$ & $10(10.9)$ \\
\hline No data & $14(5.8)$ & 13 (8.7) & 1 \\
\hline \multicolumn{4}{|l|}{ Stage } \\
\hline I & $104(43.0)$ & $64(42.7)$ & $40(43.5)$ \\
\hline II & $77(31.8)$ & $37(24.7)$ & $40(43.5)$ \\
\hline III & 45 (18.6) & $34(22.7)$ & $11(12.0)$ \\
\hline IV & $2(0.83)$ & $2(1.3)$ & $0 \quad(0.0)$ \\
\hline No data & $14 \quad(5.8)$ & $13 \quad(8.7)$ & $1 \quad(1.1)$ \\
\hline \multicolumn{4}{|c|}{ Overall survival } \\
\hline Deceased & $95(39.3)$ & $63(42.0)$ & $32(34.8)$ \\
\hline Alive & $146(60.3)$ & $86(57.3)$ & $60(65.2)$ \\
\hline No data & $1(0.41)$ & $1(0.67)$ & $\begin{array}{ll}0 & (0.0)\end{array}$ \\
\hline
\end{tabular}

NSCLC, non-small cell lung cancer; AC, adenocarcinoma; LSCC, squamous cell carcinoma. Age is expressed in years, all other data are expressed as $\mathrm{n}(\%)$.

concentrations $(70 \%, 96 \%$, absolute) and in xylene, the slides were mounted in Dako Mounting Medium using Coverslipper (Dako; Agilent Technologies, Inc.). The primary antibodies were diluted in FLEX Antibody Diluent.

Evaluation of IHC reactions. IHC slides were scanned with the Pannoramic MIDI II (3DHistech) histological scanner and evaluated using the QuantCenter (3DHistech) digital image analysis software. The cells of interest (cancer cells or normal lung alveolar cells) were distinguished from the other cellular components using the PatternQuant (3DHistech) software module. Then, the CellQuant (3DHistech) module was used to determine the percentage of positive cells and the intensity of the reaction among the selected tissue compartments only. The expression levels of SATB1 and the Ki-67 proliferative index were evaluated as previously described (59). The membranous expression of E-cadherin and $\mathrm{N}$-cadherin was assessed using a scale ranging from 0 to 3 , based on the percentage of positive cells and the intensity of the staining (Table II).

SNAIL, SLUG, and Twist1 protein expression levels were assessed using the Allred scale. This scoring system is calculated by adding a number representing the proportion of positive cells $(0-5)$ to a number reflecting the intensity of the staining (0-3) (63). The final score value ranges from 0 to 8 , where 0 indicates no positive cells, and 8 indicates more than $66 \%$ of highly positive cells (Table III). The Allred scale can be used to evaluate both nuclear and cytoplasmic stainings.

In vitro EMT induction. To induce EMT in cell culture

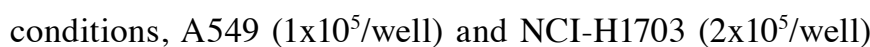
cells were seeded in 6-well plates and maintained for $24 \mathrm{~h}$ in complete culture medium (F12K and RPMI-1640, respectively), 
Table II. Scoring system used for the evaluation of membranous staining.

\begin{tabular}{ll} 
Score & \multicolumn{1}{c}{ Percentage of positive cells and intensity of staining } \\
\hline 0 & No staining is observed or staining is observed in $<10 \%$ of the tumour cells \\
1 & A faint membrane staining is observed in $>10 \%$ of the tumour cells \\
2 & A weak or moderate, complete membrane staining is observed in $>10 \%$ of the tumour cells \\
3 & A strong, complete membrane staining is observed in $>10 \%$ of the tumour cells
\end{tabular}

Table III. Allred scoring system (63).

\begin{tabular}{llll}
\hline A & Percentage of positive cells & B & Intensity of staining \\
\hline 0 & No positive cells & 0 & No detectable staining \\
1 & $<1 \%$ & 1 & Weak staining \\
2 & $1-10 \%$ & 2 & Moderate staining \\
3 & $10-33 \%$ & 3 & Strong staining \\
4 & $33-66 \%$ & & \\
5 & $>66 \%$ & & \\
\hline
\end{tabular}

The final score was calculated as a sum of the factors A and B. It fits within a range from 0 to 8 .

supplemented with 5\% FBS. Further, the medium was replaced with a fresh one, and the cells were treated with $5 \mathrm{ng} / \mathrm{ml}$ TGF- $\beta 1$ (Merck KGaA) and cultured for the next $72 \mathrm{~h}$. Every $24 \mathrm{~h}$, cell lysates were prepared and subjected to further analysis. Additionally, the cells were examined under a light microscope to track the morphological changes.

RNA isolation and cDNA synthesis. Total RNA from the NCI-H1703 and A549 cell lines was isolated using the GeneMATRIX $^{\circledR}$ Universal RNA/miRNA Purification Kit (EURx, Gdansk, Poland), according to the manufacturer's handbook. For each sample, 500 ng of total RNA was transcribed into cDNA using the iScript ${ }^{\mathrm{TM}}$ Reverse Transcription Supermix for RT-qPCR (Bio-Rad, Laboratories, Inc.) and the C1000 Touch Thermal Cycler (Bio-Rad, Laboratories, Inc.). The reaction conditions were as follows: Priming for $5 \mathrm{~min}$ at $25^{\circ} \mathrm{C}$, reverse transcription for $20 \mathrm{~min}$ at $46^{\circ} \mathrm{C}$, and final inactivation of reverse transcriptase for $1 \mathrm{~min}$ at $95^{\circ} \mathrm{C}$.

Real-time PCR. The real-time PCR method was used to determine the relative levels of $C D H 1, C D H 2, S N A I 1, S N A I 2$, and Twist 1 mRNA expression in the NCI-H1703 and A549 cell lines before and after EMT induction. The reactions were performed using the 7900 Real Time PCR System (Applied Biosystems; Thermo Fisher Scientific, Inc.) and the $\mathrm{iTaq}^{\mathrm{TM}}$ Universal Probes Supermix (Bio-Rad, Laboratories, Inc.), according to the manufacturer's instructions. The TaqMan probes used are listed in Table IV. SDHA an endogenous control gene, was further used for normalisation purposes. The reactions were carried out in triplicates under the following conditions: Initial denaturation at $94^{\circ} \mathrm{C}$ for $2 \mathrm{~min}$, followed by 45 cycles of denaturation $\left(94^{\circ} \mathrm{C}, 15 \mathrm{sec}\right)$, and annealing with elongation $\left(60^{\circ} \mathrm{C}, 1 \mathrm{~min}\right)$. The relative mRNA expression levels were calculated using the $\Delta \Delta \mathrm{Ct}$ method.
Table IV. TaqMan probes used in the experiment.

\begin{tabular}{lcl}
\hline Protein name & Gene symbol & TaqMan probe \\
\hline E-cadherin & CDH1 & Hs01023894_m1 \\
N-cadherin & CDH2 & Hs00983056_m1 \\
SNAIL & SNAI1 & Hs00195591_m1 \\
SLUG & SNAI2 & Hs00950344_m1 \\
Twist1 & Twist1 & Hs01675818_s1 \\
SDHA & SDHA & Hs99999903_m1 \\
\hline
\end{tabular}

Droplet digital PCR. The droplet digital PCR method was used to determine the absolute number of $S A T B 1 \mathrm{mRNA}$ copies in the analysed cell lines before and after EMT induction. The reaction mixture contained $3.33 \mu \mathrm{l}$ of the RT product, $1 \mu \mathrm{l}$ of the SATB1-specific TaqMan probe Hs00962580_ml (Thermo Fisher Scientific, Inc.), $5.67 \mu 1$ of the molecular biology-grade water, and $10 \mu \mathrm{l}$ of the ddPCR ${ }^{\mathrm{TM}}$ Supermix for Probes (Bio-Rad Laboratories, Inc.). A total of $20 \mu \mathrm{l}$ of the reaction mixture was loaded onto a plastic cartridge with $70 \mu \mathrm{l}$ of the Droplet Generation Oil for Probes (Bio-Rad Laboratories, Inc.) and inserted into the QX200 Droplet Generator (Bio-Rad Laboratories, Inc.). The droplets obtained from each sample were then transferred to a 96-well PCR plate (Eppendorf). PCR amplifications were carried out in the C1000 Touch Thermal Cycler (Bio-Rad Laboratories, Inc.) under the following conditions: Enzyme activation at $95^{\circ} \mathrm{C}$ for $10 \mathrm{~min}$, followed by 40 cycles of denaturation $\left(94^{\circ} \mathrm{C}, 30 \mathrm{sec}\right)$, annealing/extension $\left(60^{\circ} \mathrm{C}, 1 \mathrm{~min}\right)$, and a final enzyme deactivation at $98^{\circ} \mathrm{C}$ for $10 \mathrm{~min}$. Finally, the plate was loaded onto the QX200 Droplet Reader (Bio-Rad Laboratories, Inc.) and read automatically. The quantification of the SATB1 mRNA is presented as the total number of copies in the reaction mixture. 

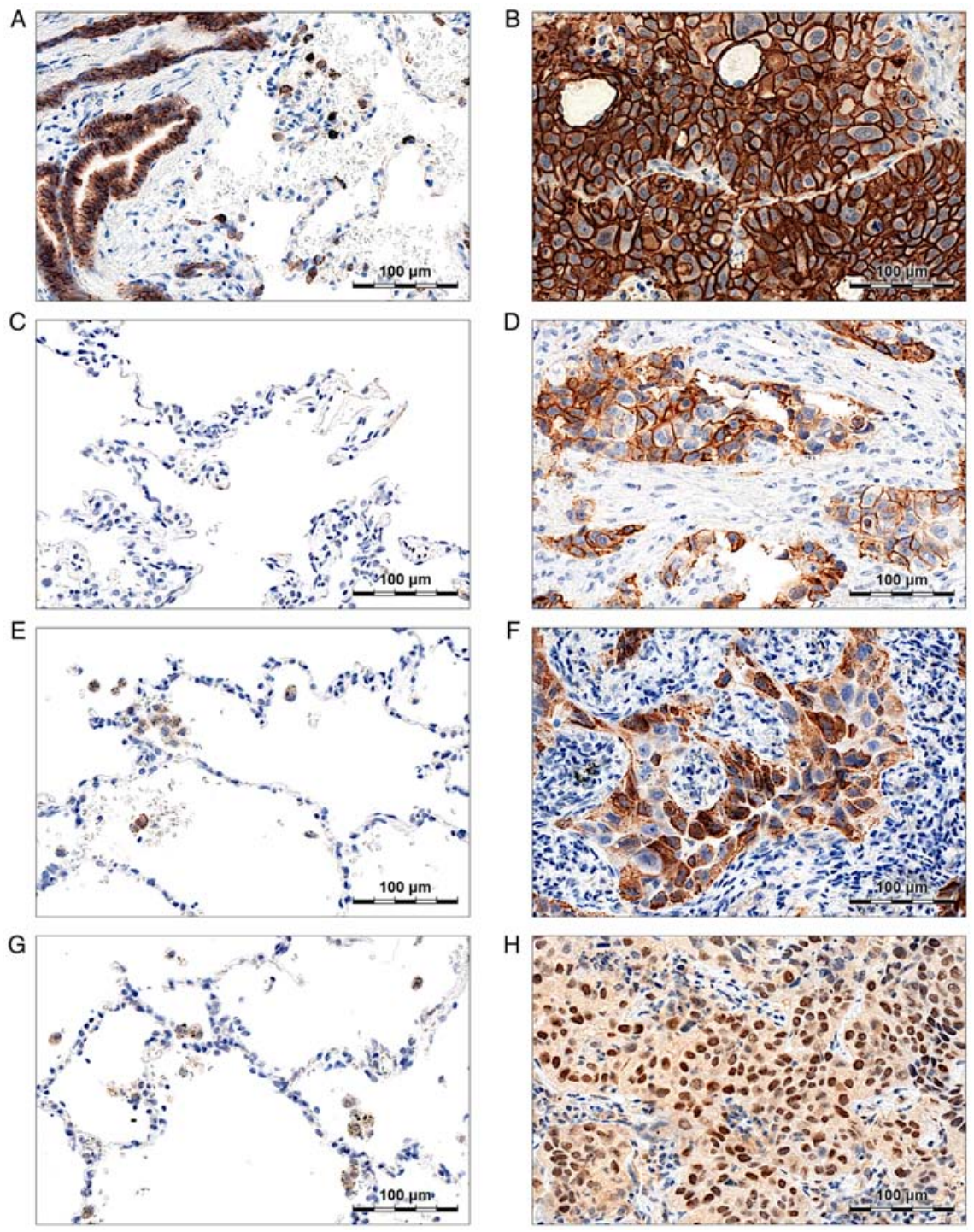

Figure 1. E-cadherin, N-cadherin, SNAIL, and SLUG expression in non-malignant lung tissue (NMLT) and non-small cell lung cancer (NSCLC) specimens. (A) E-cadherin was expressed in normal respiratory epithelium and, less abundantly, in normal lung pneumocytes. (B) A strong membranous E-cadherin staining was observed in cancer cells. (C) No N-cadherin expression was observed in NMLT samples. (D) N-cadherin was expressed in the membranes of cancer cells. (E) Normal lung pneumocytes were SNAIL-negative. However, a weak cytoplasmic staining was observed in normal lung macrophages. (F) SNAIL expression was observed in the cytoplasm of cancer cells. (G) SLUG cytoplasmic expression was present in normal lung macrophages, but not in pneumocytes. (H) In NSCLC tumours, SLUG staining was observed both in the cytoplasm and the nuclei of the cells.

Statistical analysis of the results. All the experiments, except for the IHC stainings, were performed at least in triplicates. The results were analysed with the use of Prism 8.0 software (GraphPad Software) and Statistica 13 (StatSoft, Krakow, Poland) statistical software. The Shapiro-Wilk test was utilized to determine if the sample data were normally distributed. To compare the groups of data, a non-parametric Mann-Whitney U test or a parametric Student's test was used. The correlations between the analysed parameters were checked using the Spearman's rank correlation test. The survival times were determined by using the Kaplan-Meier method, and the significance of differences was determined by a log-rank test. All the results were considered statistically significant when $\mathrm{P}<0.05$.

\section{Results}

E-cadherin is significantly overexpressed in NSCLC compared to NMLT samples. Membranous E-cadherin expression was observed both in cancer cells (Fig. 1B) and non-malignant lung tissues-respiratory epithelial cells (Fig. 1A) and pneumocytes (Fig. 1A). Strong or moderate (score $\geq 2$ ) E-cadherin staining was present in $99.17 \%$ of the analysed NSCLC cases, and the mean score values were significantly higher in NSCLC compared to the NMLT samples $(2.96 \pm 0.24$ vs. $1.10 \pm 0.64 ; \mathrm{P}<0.0001)$. No significant correlations between the expression of E-cadherin and the patient clinicopathological data were noted (Table SI).

$N$-cadherin level is related to the stage of the disease, and is correlated negatively with tumour grade. N-cadherin expression (score $\geq 1$ ) was observed in the membranes of cancer cells in $7.85 \%$ of the analysed NSCLC cases (Fig. 1D). In NMLT samples, no N-cadherin staining was detected (Fig. 1C). In the whole study cohort, mean $\mathrm{N}$-cadherin scores were significantly higher in G1-G2 tumours compared to G3 ones $(0.19 \pm 0.58$ vs. $0.03 \pm 0.24 ; \mathrm{P}=0.02$; Table SII). A similar relationship was 
Table V. SNAIL expression and clinicopathological data of NSCLC patients.

\begin{tabular}{|c|c|c|c|c|c|c|}
\hline \multirow[b]{2}{*}{ Parameters } & \multicolumn{2}{|c|}{ All cases $(\mathrm{N}=242)$} & \multicolumn{2}{|c|}{$\mathrm{AC}(\mathrm{N}=150)$} & \multicolumn{2}{|c|}{ LSCC (N=92) } \\
\hline & Score \pm SD & P-value & Score \pm SD & P-value & Score \pm SD & P-value \\
\hline \multicolumn{7}{|c|}{ Histological type } \\
\hline $\mathrm{AC}$ & $4.693 \pm 1.326$ & 0.37 & & & & \\
\hline LSCC & $4.848 \pm 1.037$ & & & & & \\
\hline \multicolumn{7}{|l|}{ Age (years) } \\
\hline$\leq 65$ & $4.596 \pm 1.256$ & 0.08 & $4.536 \pm 1.399$ & 0.19 & $4.700 \pm 0.9661$ & 0.25 \\
\hline$>65$ & $4.880 \pm 1.187$ & & $4.827 \pm 1.253$ & & $4.962 \pm 1.084$ & \\
\hline \multicolumn{7}{|l|}{ Sex } \\
\hline Male & $4.733 \pm 1.228$ & 0.89 & $4.706 \pm 1.352$ & 0.86 & $4.770 \pm 1.039$ & 0.49 \\
\hline Female & $4.758 \pm 1.209$ & & $4.677 \pm 1.300$ & & $4.933 \pm 0.9803$ & \\
\hline \multicolumn{7}{|c|}{ Malignancy grade } \\
\hline $\mathrm{G} 1, \mathrm{G} 2$ & $4.794 \pm 1.215$ & 0.38 & $4.684 \pm 1.378$ & 0.99 & $4.899 \pm 1.033$ & 0.16 \\
\hline G3 & $4.678 \pm 1.244$ & & $4.703 \pm 1.279$ & & $4.538 \pm 1.050$ & \\
\hline \multicolumn{7}{|l|}{ Tumour size } \\
\hline pT1 & $4.605 \pm 1.276$ & 0.25 & $4.500 \pm 1.388$ & 0.27 & $4.900 \pm 0.8522$ & 0.95 \\
\hline pT2-pT4 & $4.803 \pm 1.218$ & & $4.765 \pm 1.325$ & & $4.845 \pm 1.091$ & \\
\hline \multicolumn{7}{|c|}{ Lymph nodes } \\
\hline pNO & $4.671 \pm 1.239$ & 0.15 & $4.656 \pm 1.383$ & 0.71 & $4.692 \pm 0.9988$ & 0.02 \\
\hline $\mathrm{pN} 1, \mathrm{pN} 2$ & $4.914 \pm 1.185$ & & $4.759 \pm 1.228$ & & $5.222 \pm 1.050$ & \\
\hline \multicolumn{7}{|l|}{ Stage } \\
\hline I & $4.529 \pm 1.238$ & 0.02 & $4.469 \pm 1.368$ & 0.16 & $4.625 \pm 1.005$ & 0.04 \\
\hline II-IV & $4.911 \pm 1.216$ & & $4.822 \pm 1.326$ & & $5.039 \pm 1.038$ & \\
\hline
\end{tabular}

NSCLC, non-small cell lung carcinoma; AC, adenocarcinoma; LSCC, squamous cell carcinoma. Significant P-values are provided in bold.

also observed in $\mathrm{AC}$ cases analysed separately $(0.17 \pm 0.60$ vs. $0.01 \pm 0.12 ; \mathrm{P}=0.05$; Table SII). Moreover, N-cadherin overexpression was associated with a more advanced stage of the disease, both in the whole study cohort $(0.17 \pm 0.51$ in stage II-IV tumours vs. $0.05 \pm 0.35$ in stage I tumours; $\mathrm{P}=0.007$; Table SII), and in the LSCC subtype $(0.31 \pm 0.68$ in stage II-IV tumours vs. $0.05 \pm 0.32$ in stage I tumours; $\mathrm{P}=0.02$; Table $\mathrm{SII})$.

In LSCC, SNAIL overexpression was associated with an advanced stage of the disease and the presence of lymph node metastasis. SNAIL was highly expressed in the cytoplasm of cancer cells (Fig. 1F) and, less abundantly, in the cytoplasm of normal lung macrophages (Fig. 1E). A total of $82.64 \%$ of NSCLC specimens were SNAIL-positive (Allred score $>3$ ). No SNAIL expression was observed in non-malignant lung alveoli (Fig. 1E) and bronchial epithelium. Although mean SNAIL scores did not differ between particular NSCLC subtypes (Table V), the exact expression patterns and associations with the clinicopathological data seemed to be dependent on the tumour histology. While in AC there was no relationship between SNAIL expression and the presence of lymph node metastasis, SNAIL was significantly overexpressed in $\mathrm{pN} 1$ and $\mathrm{pN} 2$ tumours compared to $\mathrm{pN} 0$ ones $(5.22 \pm 1.05$ vs. 4.69 $\pm 1.00 ; \mathrm{P}=0.02$; Table V) in LSCC. Additionally, in LSCC, an elevated SNAIL level was associated with a more advanced stage of the disease; in stage II-IV tumours mean
SNAIL scores were significantly higher compared to stage I $(5.04 \pm 1.04$ vs. $4.63 \pm 1.01 ; \mathrm{P}=0.04$; Table V). Similar associations between SNAIL expression and the stage of the disease were also observed in the whole study cohort, but not in the AC subtype analysed separately (Table V).

Relationships between SLUG expression and the patient clinicopathological data are dependent on protein localisation (nuclear vs. cytoplasmic) and tumour histology. SLUG staining was detected in the cytoplasm and nuclei of cancer cells (Fig. 1H) and in the cytoplasm of normal lung macrophages (Fig. 1G). We observed cytoplasmic SLUG (SLUG C) expression (Allred score $>3$ ) in $75.62 \%$ of NSCLC cases, whereas nuclear expression (SLUG N; Allred score $>3$ ) was present in $51.24 \%$ of the samples. In $50.83 \%$ of the analysed cases, SLUG was expressed both in the cytoplasm and nuclei of the cells.

SLUG C expression patterns differed visibly depending on the tumour histology. In AC, mean SLUG C scores were significantly higher in $\mathrm{G} 3$ tumours compared to $\mathrm{G} 1$ and $\mathrm{G} 2$ ones $(5.70 \pm 0.95$ vs. $5.32 \pm 1.17 ; \mathrm{P}=0.05$; Table VI). The association between SLUG C expression and the tumour malignancy grade was also present in the whole study cohort (Table VI). At the same time, in LSCC, the level of SLUG C seemed to be positively associated with the tumour size $(5.44 \pm 1.02$ in pT2-pT4 tumours vs. $4.75 \pm 1.58$ in pT1 tumours; $\mathrm{P}=0.04$; 
Table VI. Cytoplasmic SLUG expression and clinicopathological data of the NSCLC patients.

\begin{tabular}{|c|c|c|c|c|c|c|}
\hline \multirow[b]{2}{*}{ Parameters } & \multicolumn{2}{|c|}{ All cases $(\mathrm{N}=242)$} & \multicolumn{2}{|c|}{$\mathrm{AC}(\mathrm{N}=150)$} & \multicolumn{2}{|c|}{$\operatorname{LSCC}(\mathrm{N}=92)$} \\
\hline & Score \pm SD & P-value & Score \pm SD & P-value & Score \pm SD & P-value \\
\hline \multicolumn{7}{|c|}{ Histological type } \\
\hline $\mathrm{AC}$ & $5.507 \pm 1.079$ & 0.11 & & & & \\
\hline LSCC & $5.293 \pm 1.191$ & & & & & \\
\hline \multicolumn{7}{|l|}{ Age (years) } \\
\hline$\leq 65$ & $5.266 \pm 1.303$ & 0.16 & $5.333 \pm 1.233$ & 0.21 & $5.150 \pm 1.424$ & 0.47 \\
\hline$>65$ & $5.556 \pm 0.9408$ & & $5.654 \pm 0.9105$ & & $5.404 \pm 0.9754$ & \\
\hline \multicolumn{7}{|l|}{ Sex } \\
\hline Male & $5.370 \pm 1.151$ & 0.53 & $5.506 \pm 1.054$ & 0.78 & $5.180 \pm 1.258$ & 0.29 \\
\hline Female & $5.505 \pm 1.090$ & & $5.508 \pm 1.120$ & & $5.500 \pm 1.042$ & \\
\hline \multicolumn{7}{|c|}{ Malignancy grade } \\
\hline $\mathrm{G} 1, \mathrm{G} 2$ & $5.303 \pm 1.181$ & 0.03 & $5.316 \pm 1.169$ & 0.05 & $5.291 \pm 1.200$ & 0.94 \\
\hline G3 & $5.644 \pm 0.9880$ & & $5.703 \pm 0.9469$ & & $5.308 \pm 1.182$ & \\
\hline \multicolumn{7}{|l|}{ Tumour size } \\
\hline pT1 & $5.237 \pm 1.284$ & 0.09 & $5.411 \pm 1.125$ & 0.31 & $4.750 \pm 1.585$ & 0.04 \\
\hline pT2-pT4 & $5.487 \pm 1.048$ & & $5.531 \pm 1.073$ & & $5.437 \pm 1.024$ & \\
\hline \multicolumn{7}{|c|}{ Lymph nodes } \\
\hline pNO & $5.453 \pm 1.145$ & 0.49 & $5.615 \pm 1.019$ & 0.09 & $5.215 \pm 1.281$ & 0.37 \\
\hline $\mathrm{pN} 1, \mathrm{pN} 2$ & $5.370 \pm 1.089$ & & $5.315 \pm 1.163$ & & $5.481 \pm 0.9352$ & \\
\hline \multicolumn{7}{|l|}{ Stage } \\
\hline I & $5.375 \pm 1.232$ & 0.88 & $5.656 \pm 0.9955$ & 0.08 & $4.925 \pm 1.439$ & 0.02 \\
\hline II-IV & $5.427 \pm 1.053$ & & $5.329 \pm 1.155$ & & $5.569 \pm 0.8776$ & \\
\hline
\end{tabular}

NSCLC, non-small cell lung carcinoma; AC, adenocarcinoma; LSCC, squamous cell carcinoma. Significant P-values are provided in bold.

Table VI) and the stage of the disease $(5.57 \pm 0.88$ in stage II-IV tumours vs. $4.92 \pm 1.44$ in stage I tumours; $\mathrm{P}=0.02$; Table VI).

SLUG $\mathrm{N}$ was significantly overexpressed in LSCC

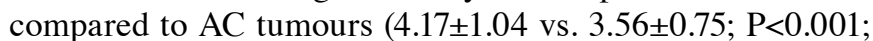
Table VII). In LSCC, the level of SLUG N was positively associated with the tumour size $(4.27 \pm 1.04$ in pT2-pT4 tumours vs. $3.80 \pm 1.01$ in pT1 tumours; $\mathrm{P}=0.04$; Table VII) and the stage of the disease $(4.33 \pm 0.97$ in stage II-IV tumours vs. $3.95 \pm 1.11$ in stage I tumours; $\mathrm{P}=0.02$; Table VII). A positive relationship between tumour size and SLUG N expression was also observed in the whole study cohort, but not in the AC subtype (Table VII). In AC, SLUG N expression level was revealed to be associated with the patient sex: It was significantly higher in men than in women (3.69 \pm 0.76 vs. $3.39 \pm 0.70$, respectively; $\mathrm{P}=0.01$; Table VII).

Twistl is expressed mainly in LSCC tumours, and its expression levels are correlated with the stage of the disease. Twist1 expression was observed in the nuclei of cancer cells (Fig. 2C) and in the nuclei of infiltrating lymphocytes (Fig. 2B). In NMLT samples, no Twist1 staining was detected (Fig. 2A). A total of $12.81 \%$ of the analysed NSCLC samples were Twist1-positive (Allred score $>3$ ). Twist1 expression levels were related to the tumour histology; in LSCC, mean score values were significantly higher compared to $\mathrm{AC}$ (3.50 \pm 1.19 vs. $2.74 \pm 0.62$, respectively; $\mathrm{P}<0.001$; Table SIII).
Moreover, in LSCC, Twistl expression was positively associated with the stage of the disease $(3.73 \pm 1.33$ in stage II-IV tumours vs. $3.20 \pm 0.94$ in stage I tumours; $\mathrm{P}=0.04$; Table SIII). Inversely, in AC, a negative relationship between Twist1 level and the tumour size was observed; in pT2-pT4 tumours, Twist1 expression was significantly decreased compared to pT1 ones ( $2.62 \pm 0.68$ vs. $2.86 \pm 0.55$, respectively; $\mathrm{P}=0.02$; Table SIII).

SATB1 scores are positively correlated with SNAIL, SLUG, and Twistl expression. Further analysis revealed that SNAIL, SLUG, and Twist1 expression levels were positively correlated with SATB1 scores, as assessed in our previous study (59). In the whole study cohort, we observed a moderate positive correlation between the expression of SATB1 and SLUG N $(\mathrm{R}=0.449$; $\mathrm{P}<0.0001$; Table VIII; Fig. 3G), and a low positive correlation between the expression of SATB1 and SLUG C $(\mathrm{R}=0.288$; $\mathrm{P}<0.0001$; Table VIII; Fig. 3D). SATB1 scores were also correlated positively with Twist1 and SNAIL levels $(\mathrm{R}=0.264 ; \mathrm{P}<0.0001$ and $\mathrm{R}=0.129 ; \mathrm{P}<0.045$, respectively; Table VIII; Fig. 3J and A, respectively).

Positive correlations between the expression levels of SATB1 and SLUG N on the one hand, and the expression levels of SATB1 and SLUG C on the other were also observed in the $\mathrm{AC}$ and LSCC subtypes analysed separately. $\mathrm{R}$ values were especially high in LSCC: 0.424 for SATB1/SLUG N and 0.403 for SATB1/SLUG C correlation (Table VIII; Fig. 3). However, 
Table VII. Nuclear SLUG expression and clinicopathological data of the NSCLC patients.

\begin{tabular}{|c|c|c|c|c|c|c|}
\hline \multirow[b]{2}{*}{ Parameters } & \multicolumn{2}{|c|}{ All cases $(\mathrm{N}=242)$} & \multicolumn{2}{|c|}{$\mathrm{AC}(\mathrm{N}=150)$} & \multicolumn{2}{|c|}{ LSCC (N=92) } \\
\hline & Score \pm SD & P-value & Score \pm SD & P-value & Score \pm SD & P-value \\
\hline \multicolumn{7}{|c|}{ Histological type } \\
\hline $\mathrm{AC}$ & $3.560 \pm 0.7462$ & $<0.001$ & & & & \\
\hline LSCC & $4.174 \pm 1.044$ & & & & & \\
\hline \multicolumn{7}{|l|}{ Age (years) } \\
\hline$\leq 65$ & $3.725 \pm 0.9610$ & 0.21 & $3.449 \pm 0.7580$ & 0.09 & $4.200 \pm 1.091$ & 0.47 \\
\hline$>65$ & $3.850 \pm 0.8833$ & & $3.654 \pm 0.7273$ & & $4.154 \pm 1.017$ & \\
\hline \multicolumn{7}{|l|}{ Sex } \\
\hline Male & $3.884 \pm 0.9433$ & 0.05 & $3.694 \pm 0.7563$ & 0.01 & $4.148 \pm 1.108$ & 0.29 \\
\hline Female & $3.642 \pm 0.8619$ & & $3.385 \pm 0.7003$ & & $4.200 \pm 0.9248$ & \\
\hline \multicolumn{7}{|c|}{ Malignancy grade } \\
\hline $\mathrm{G} 1, \mathrm{G} 2$ & $3.858 \pm 0.9766$ & 0.22 & $3.474 \pm 0.7019$ & 0.18 & $4.228 \pm 1.062$ & 0.94 \\
\hline G3 & $3.678 \pm 0.7996$ & & $3.649 \pm 0.7840$ & & $3.846 \pm 0.8987$ & \\
\hline \multicolumn{7}{|l|}{ Tumour size } \\
\hline pT1 & $3.526 \pm 0.7912$ & 0.002 & $3.429 \pm 0.6838$ & 0.12 & $3.800 \pm 1.005$ & 0.04 \\
\hline pT2-pT4 & $3.908 \pm 0.9653$ & & $3.593 \pm 0.7710$ & & $4.268 \pm 1.041$ & \\
\hline \multicolumn{7}{|c|}{ Lymph nodes } \\
\hline pNO & $3.752 \pm 0.8662$ & 0.35 & $3.542 \pm 0.6793$ & 0.67 & $4.062 \pm 1.014$ & 0.37 \\
\hline $\mathrm{pN} 1, \mathrm{pN} 2$ & $3.877 \pm 1.017$ & & $3.593 \pm 0.8582$ & & $4.444 \pm 1.086$ & \\
\hline \multicolumn{7}{|l|}{ Stage } \\
\hline I & $3.673 \pm 0.8527$ & 0.09 & $3.500 \pm 0.5909$ & 0.85 & $3.950 \pm 1.108$ & 0.02 \\
\hline II-IV & $3.871 \pm 0.9792$ & & $3.548 \pm 0.8505$ & & $4.333 \pm 0.9730$ & \\
\hline
\end{tabular}

NSCLC, non-small cell lung carcinoma; AC, adenocarcinoma; LSCC, squamous cell carcinoma. Significant P-values are provided in bold.

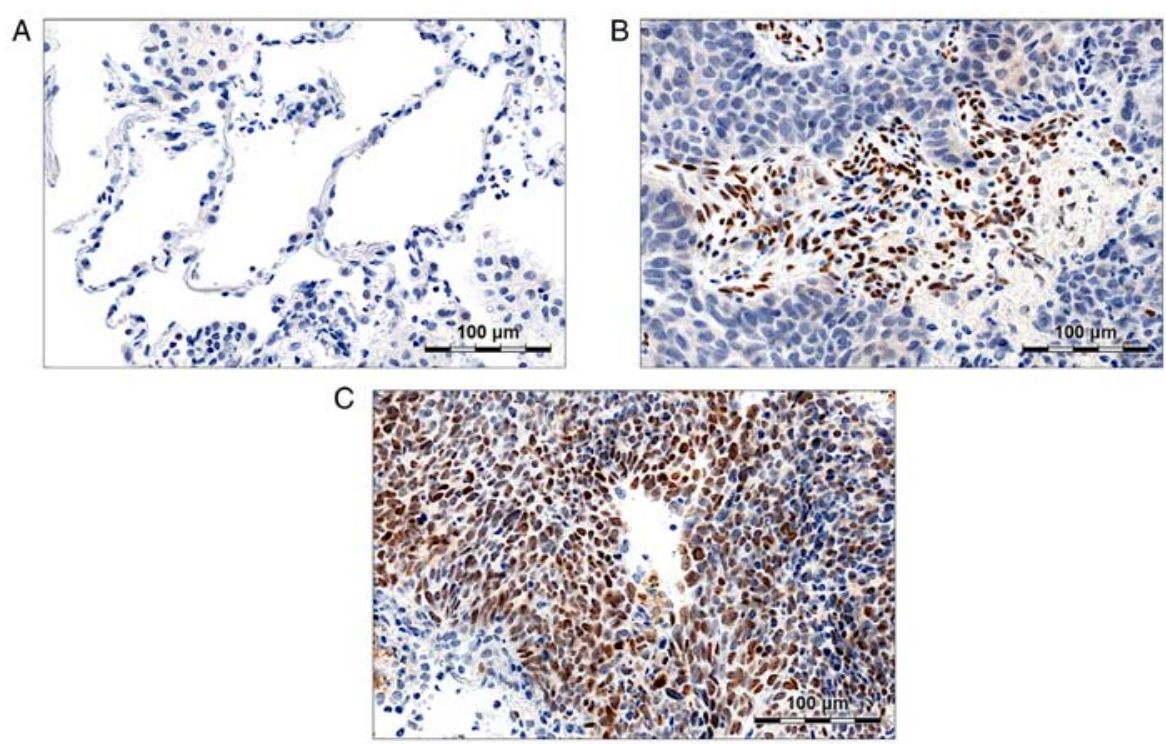

Figure 2. Twist1 expression in non-malignant lung tissue (NMLT) and non-small cell lung cancer (NSCLC) specimens. (A) No Twist1 staining was observed in normal lung pneumocytes. (B) Twist1 was intensively expressed in the nuclei of tumour infiltrating lymphocytes. (C) Twist1 staining was observed in the nuclei of NSCLC cells.

a significant correlation between SATB1 and Twist1 expressions was found only in $\mathrm{AC}(\mathrm{R}=0.218$; $\mathrm{P}=0.008$; Table VIII; Fig. 3K).
Expression of EMT markers is positively correlated with Ki67 scores. The expression of all of the markers analysed in the whole study cohort was found to be positively correlated with 
Table VIII. Correlations between the expression of SATB1 and E-cadherin, N-cadherin, SNAIL, SLUG, and Twist1 proteins.

\begin{tabular}{|c|c|c|c|c|c|c|}
\hline \multirow[b]{2}{*}{ Protein } & \multicolumn{2}{|c|}{ NSCLC } & \multicolumn{2}{|c|}{$\mathrm{AC}$} & \multicolumn{2}{|c|}{ LSCC } \\
\hline & Spearman's R & P-value & Spearman's R & P-value & Spearman's R & P-value \\
\hline E-cadherin & 0.109 & 0.090 & 0.069 & 0.400 & 0.143 & 0.174 \\
\hline N-cadherin & 0.080 & 0.215 & -0.004 & 0.963 & 0.126 & 0.232 \\
\hline SNAIL & 0.129 & 0.045 & 0.092 & 0.261 & 0.152 & 0.148 \\
\hline SLUG C & 0.288 & $<0.0001$ & 0.294 & $<0.001$ & 0.403 & $<0.0001$ \\
\hline SLUG N & 0.449 & $<0.0001$ & 0.365 & $<0.0001$ & 0.424 & $<0.0001$ \\
\hline Twist1 & 0.264 & $<0.0001$ & 0.218 & 0.008 & 0.144 & 0.169 \\
\hline
\end{tabular}

SATB1, special AT-rich binding protein 1; NSCLC, non-small cell lung carcinoma; AC, adenocarcinoma; LSCC, squamous cell carcinoma. C, cytoplasmic; N, nuclear. Significant P-values are provided in bold.
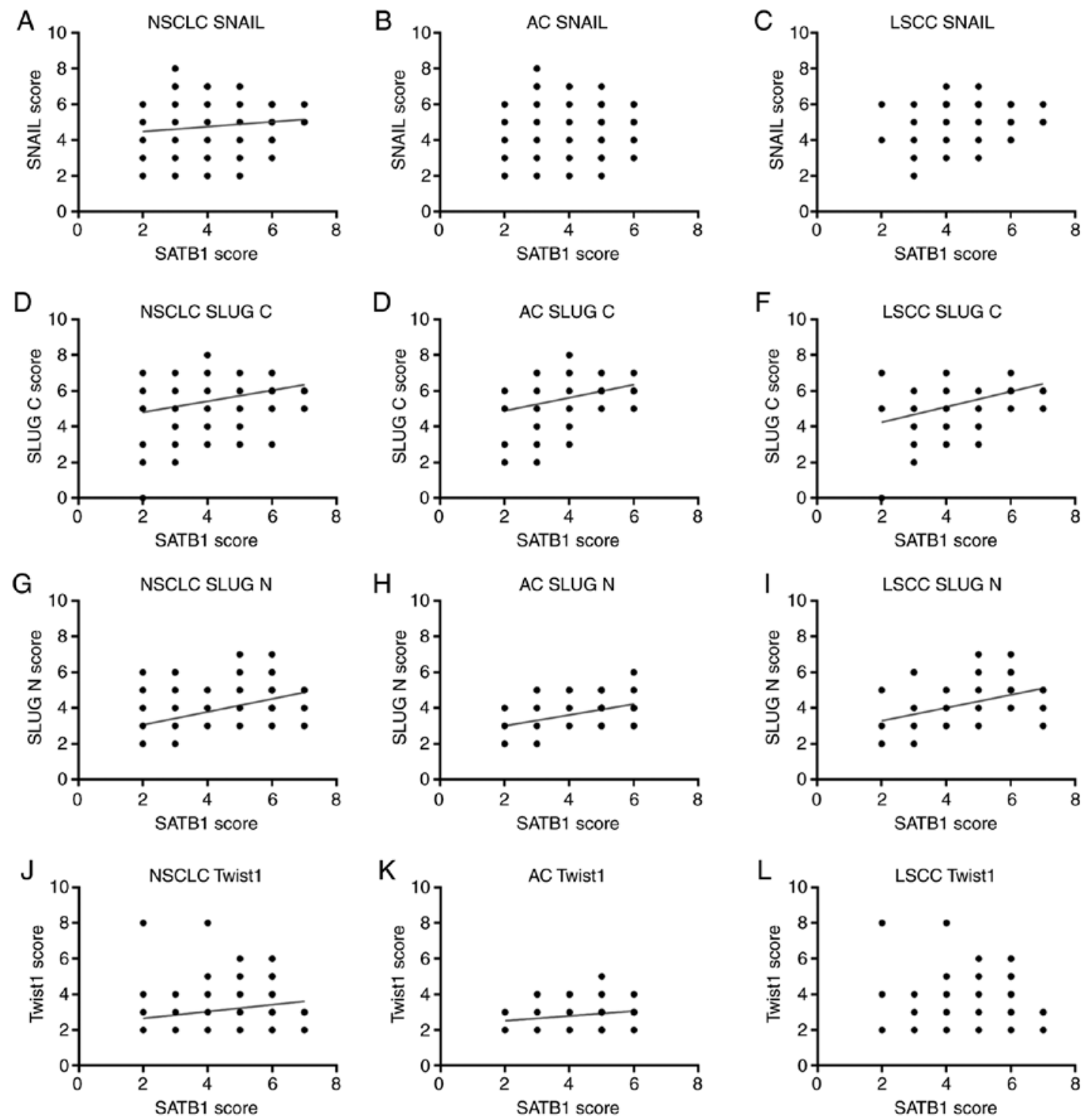

Figure 3. Correlations between the expression of special AT-rich binding protein 1 (SATB1) and E-cadherin, N-cadherin, SNAIL, SLUG, and Twist1 proteins in the whole non-small cell lung cancer (NSCLC) study cohort, as well as in adenocarcinoma (AC) and squamous cell carcinoma (LSCC) analysed separately. (A-C) A positive correlation between the expression of SATB1 and SNAIL was observed only in the whole study cohort ( $R=0.129 ; \mathrm{P}=0.045)$. (D-F) Cytoplasmic SLUG expression was correlated positively with the expression of SATB1 both in the whole study cohort and in the particular NSCLC subtypes (NSCLC: $\mathrm{R}=0.288 ; \mathrm{P}<0.0001$; AC: $\mathrm{R}=0.294$; $\mathrm{P}<0.001$; LSCC: $\mathrm{R}=0.403$; $\mathrm{P}<0.0001$ ). (G-I) Nuclear SLUG expression was correlated positively with the expression of SATB1 both in the whole study cohort and in the particular NSCLC subtypes (NSCLC: $\mathrm{R}=0.449$; $\mathrm{P}<0.0001$; AC: R=0.365; P<0.0001; LSCC: $\mathrm{R}=0.424 ; \mathrm{P}<0.0001)$. (J-L) There was a positive correlation between Twist1 and SATB1 expressions in NSCLC and AC, but not in LSCC tumours (NSCLC: $\mathrm{R}=0.264 ; \mathrm{P}<0.0001 ; \mathrm{AC}: \mathrm{R}=218 ; \mathrm{P}=0.008)$. 
Table IX. Correlations between the expression of E-cadherin, N-cadherin, SNAIL, SLUG, and Twist1 and the Ki-67 proliferative index.

\begin{tabular}{|c|c|c|c|c|c|c|}
\hline \multirow[b]{2}{*}{ Protein } & \multicolumn{2}{|c|}{ NSCLC } & \multicolumn{2}{|c|}{$\mathrm{AC}$} & \multicolumn{2}{|c|}{ LSCC } \\
\hline & Spearman's R & P-value & Spearman's R & P-value & Spearman's R & P-value \\
\hline E-cadherin & 0.202 & 0.002 & 0.249 & 0.002 & 0.060 & 0.569 \\
\hline $\mathrm{N}$-cadherin & 0.196 & 0.002 & 0.173 & 0.035 & 0.182 & 0.082 \\
\hline SNAIL & 0.372 & $<0.0001$ & 0.351 & $<0.0001$ & 0.449 & $<0.0001$ \\
\hline SLUG C & 0.228 & $<0.001$ & 0.198 & 0.015 & 0.410 & $<0.0001$ \\
\hline SLUG N & 0.347 & $<0.0001$ & 0.235 & 0.004 & 0.284 & 0.006 \\
\hline Twist1 & 0.215 & 0.001 & -0.036 & 0.662 & 0.299 & 0.004 \\
\hline
\end{tabular}

NSCLC, non-small cell lung carcinoma; AC, adenocarcinoma; LSCC, squamous cell carcinoma. C, cytoplasmic; N, nuclear. Significant P-values are provided in bold.
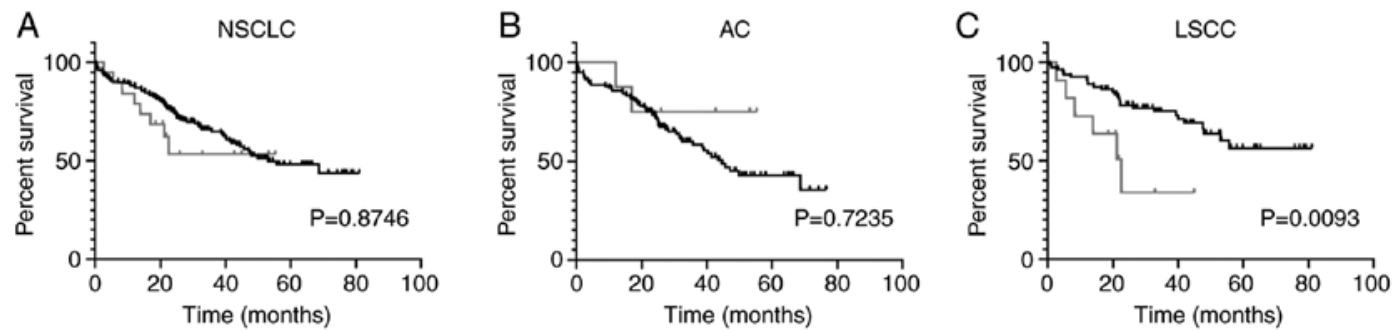

$$
\begin{aligned}
& -\mathrm{N} \text {-cadherin score }<1 \\
& +\mathrm{N} \text {-cadherin score } \geq 1
\end{aligned}
$$

Figure 4. Prognostic significance of N-cadherin expression. Kaplan-Meier's survival curves for non-small cell lung cancer (NSCLC), adenocarcinoma (AC), and squamous cell carcinoma (LSCC) patients. (A) In the whole NSCLC study cohort, there was no significant difference in the overall survival (OS) of patients with low (score $<1$ ) and elevated (score $\geq 1) \mathrm{N}$-cadherin expression $(\mathrm{P}=0.8746)$. (B) No significant impact of $\mathrm{N}$-cadherin expression on patient OS was seen also in the AC subtype analysed separately $(\mathrm{P}=0.7235)$. (C) Elevated $\mathrm{N}$-cadherin scores $(\geq 1)$ had a negative prognostic significance in LSCC ( $\mathrm{P}=0.0093)$,
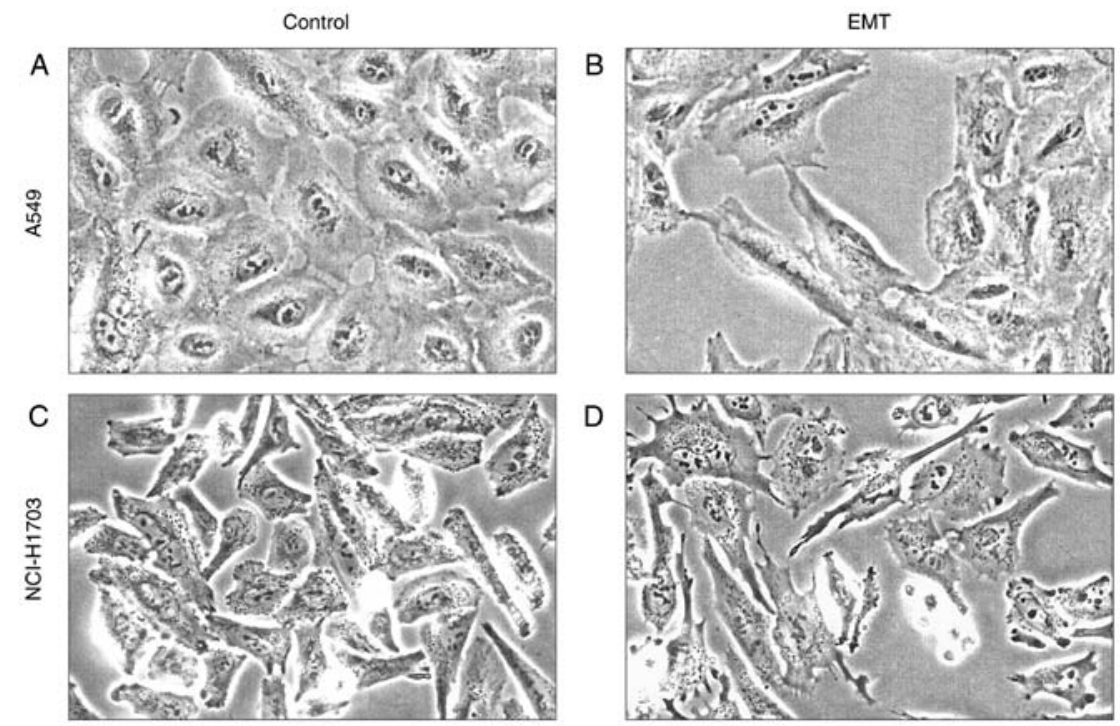

Figure 5. Changes in cell morphology after $48 \mathrm{~h}$ of transforming growth factor (TGF)- $\beta 1$ exposure. (A) Control A549 cells displaying their usual cobblestone-like morphology. (B) A549 cells $48 \mathrm{~h}$ after induction of epithelial-mesenchymal transition (EMT) became elongated and spindle-shaped. Moreover, they grew dispersed and showed reduced cell-to-cell contact. (C) Naturally elongated control NCI-H1703 cells. (D) NCI-H1703 cells, 48 h after EMT induction, developed numerous cytoplasmic extensions, probably associated with an enhanced cell motility [64].

Ki67 scores, as assessed in our previous study (59). The correlation coefficients were particularly high for SNAIL and SLUG $\mathrm{N}(\mathrm{R}=0.372 ; \mathrm{P}<0.0001$ and $\mathrm{R}=0.347 ; \mathrm{P}<0.0001$, respectively;
Table IX). Significant positive correlations between the expression of Ki67 and E-cadherin, N-cadherin, SNAIL, SLUG C, and SLUG $\mathrm{N}$ were also detected in the AC subtype (Table IX). 

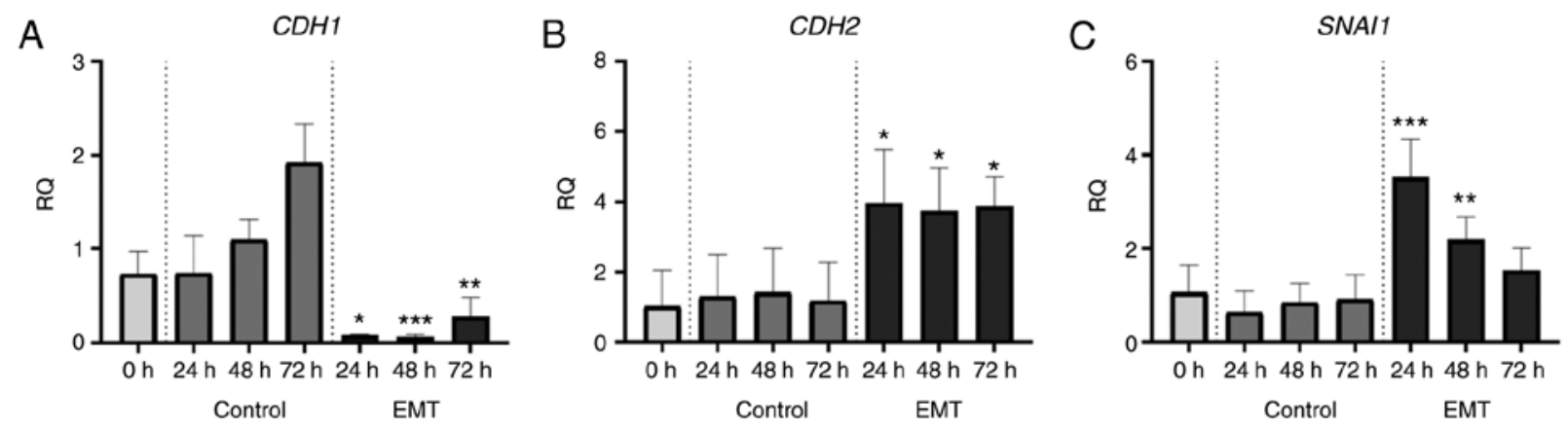

D

SNAI2

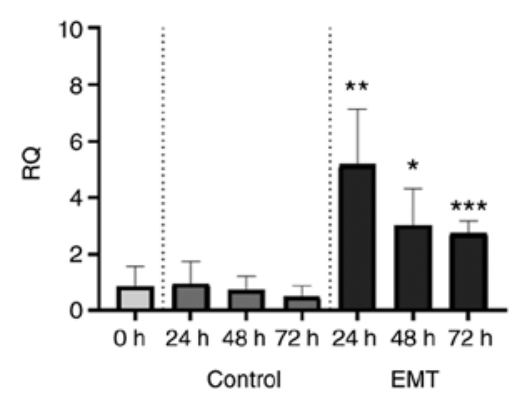

$\mathrm{E}$

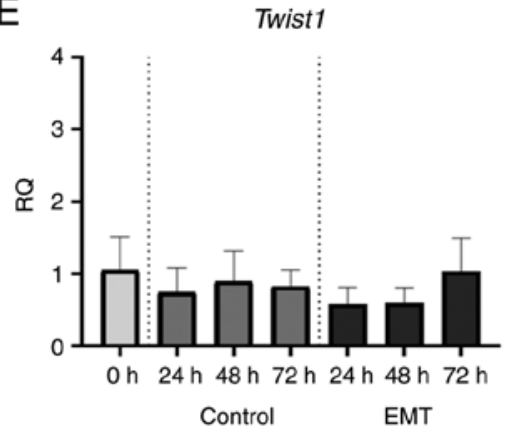

Figure 6. Epithelial-mesenchymal transition (EMT) induction in A549 cells resulted in significant changes in the expression of key EMT-associated genes. (A) $C D H 1$ expression decreased about 10-fold. (B-D) Expression levels of $C D H 2, S N A I 1$, and $S N A I 2$ increased significantly. (E) Expression of Twist1 remained unchanged compared to the control cells. ${ }^{*} \mathrm{P}<0.05,{ }^{* *} \mathrm{P}<0.01$ and ${ }^{* * * *} \mathrm{P}<0.001$. Error bars stand for standard deviation.

In LSCC, Ki67 expression correlated moderately with the expression of SNAIL and SLUG C $(\mathrm{R}=0.449 ; \mathrm{P}<0.0001$ and $\mathrm{R}=0.410 ; \mathrm{P}<0.0001$, respectively; Table IX), and more weakly with the expression of SLUG N and Twist1 $(\mathrm{R}=0.284 ; \mathrm{P}<0.006$ and $\mathrm{R}=0.299 ; \mathrm{P}<0.004$, respectively; Table IX). Interestingly, in LSCC, no associations between Ki67, E-cadherin, and $\mathrm{N}$-cadherin levels were observed (Table IX).

$N$-cadherin expression is a negative prognostic factor for LSCC patients. In order to determine the impact of $\mathrm{N}$-cadherin expression on patient survival, Kaplan-Meier's survival curves were compared using the log-rank (Mantel-Cox) test. The results revealed that an elevated $\mathrm{N}$-cadherin level (score $\geq 1$ ) was a significant negative prognostic factor for LSCC patients $(\mathrm{P}=0.0093$; Fig. 4C), but not for AC patients $(\mathrm{P}=0.7235$; Fig. 4B). N-cadherin expression lacked a prognostic significance in the whole study cohort as well ( $\mathrm{P}=0.8746$; Fig. 4A).

Apart from $\mathrm{N}$-cadherin, none of the markers analysed (E-cadherin, SNAIL, SLUG, or Twist1) was observed to have a significant impact on NSCLC patient survival.

TGF- $\beta 1$ treatment successfully induces EMT in NSCLC cell line. To determine whether SATB1 expression changes during the EMT process, we induced EMT in vitro in the A549 (AC) and NCI-H1703 (LSCC) cell lines using TGF- $\beta 1$. Forty eight hours after exposure to TGF- $\beta 1$, we observed significant morphological changes in the cultured cells, which indicated a shift from an epithelial to a mesenchymal phenotype. A549 cells lost their usual cobblestone-like morphology (Fig. 5A) and became elongated and spindle-shaped. Moreover, they grew dispersed and showed reduced cell-to-cell contact (Fig. 5B). In NCI-H1703 cells, due to their normally elongated shape (Fig. 5C), morphological changes were less evident but still noticeable. Additionally, after EMT induction, these cells developed numerous cytoplasmic extensions, probably associated with an enhanced cell motility (64) (Fig. 5D).

These morphological transformations were accompanied with a gradual shift from epithelial to mesenchymal gene expression profiles. To track these changes, we performed real-time PCR assays and analysed the expression of key EMT-related genes, $C D H 1, C D H 2$, SNAI1, SNAI2, and TWIST1 (coding for E-cadherin, N-cadherin, SNAIL, SLUG, and Twist1, respectively). After EMT induction, in the A549 cell line we observed about a 10 -fold decrease in $\mathrm{CDH} 1$ expression (Fig. 6A) and a significant increase in the expression of $\mathrm{CDH} 2$, SNAII and SNAI2 (Fig. 6B-D). In the NCI-H1703 cells, the expression levels of $C D H 1$ remained unchanged after TGF- $\beta 1$ exposure (Fig. 7A), while the expression of $\mathrm{CDH} 2, \mathrm{SNAI1}$, and SNAI2 increased significantly (Fig. 7B-D). In both cell lines, EMT induction had no effect on Twist1 mRNA levels (Figs. 6E and 7E).

SATB1 expression in A549 and NCI-H1703 cell lines is significantly increased after EMT induction. In order to investigate whether SATBl expression in NSCLC cell lines changes during EMT, we used the Droplet Digital PCR method to assess $S A T B 1 \mathrm{mRNA}$ levels in the cell culture lysates obtained from the cells after TGF- $\beta 1$ treatment and from the control ones. In both of the analysed cell lines (A549 and NCI-H1703), induction of EMT resulted in a significant increase in SATB1 expression levels. However, the exact $S A T B 1$ expression patterns were different depending on the cell line.

In the control (untreated A549 cells), SATB1 mRNA level gradually increased during the time of the culture, reaching its maximum value $(62.00 \pm 40.51 \mathrm{mRNA}$ copies $)$ after $72 \mathrm{~h}$. 

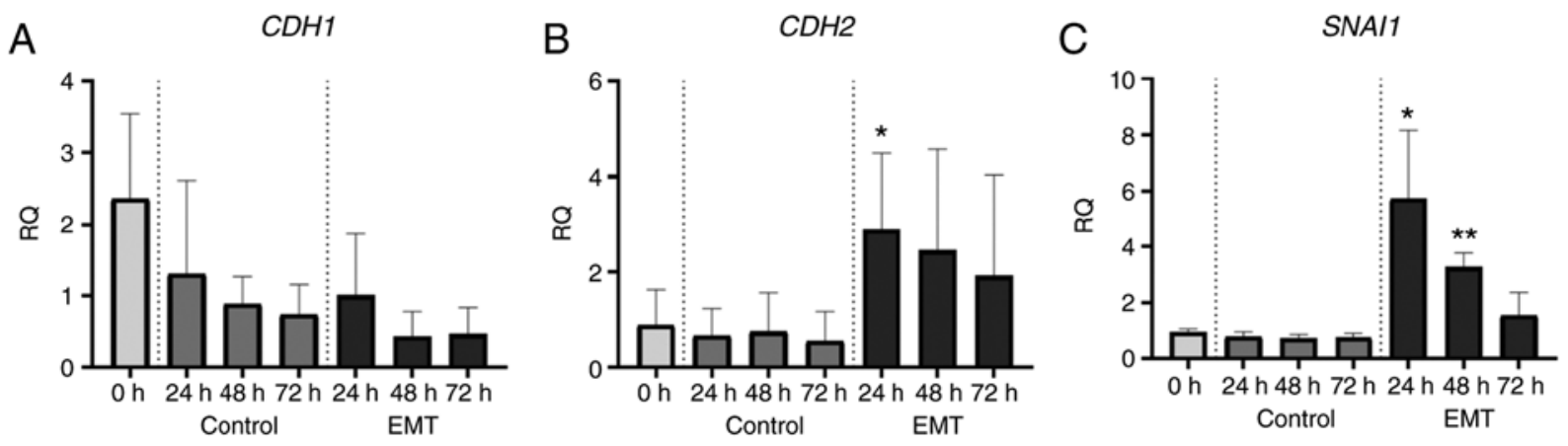

D

SNAI2

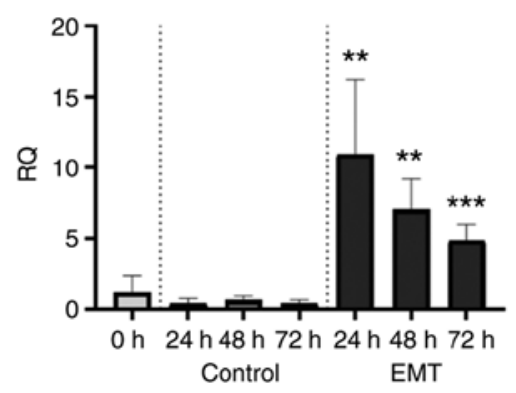

$\mathrm{E}$

Twist1

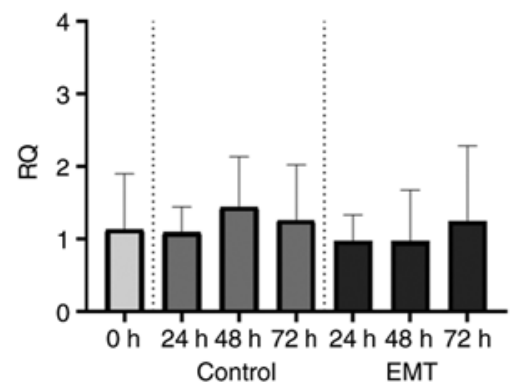

Figure 7. Epithelial-mesenchymal transition (EMT) induction in NCI-H1703 cells resulted in significant (but less evident than in A549 cells) changes in the expression of key EMT-associated genes. (A) CDH1 expression did not change. (B-D) Expression levels of $C D H 2$, SNAII and SNAI2 increased significantly. (E) Expression of Twistl remained unchanged compared to the control cells. ${ }^{*} \mathrm{P}<0.05,{ }^{* * *} \mathrm{P}<0.01$ and ${ }^{* * *} \mathrm{P}<0.001$. Error bars stand for standard deviation.

A

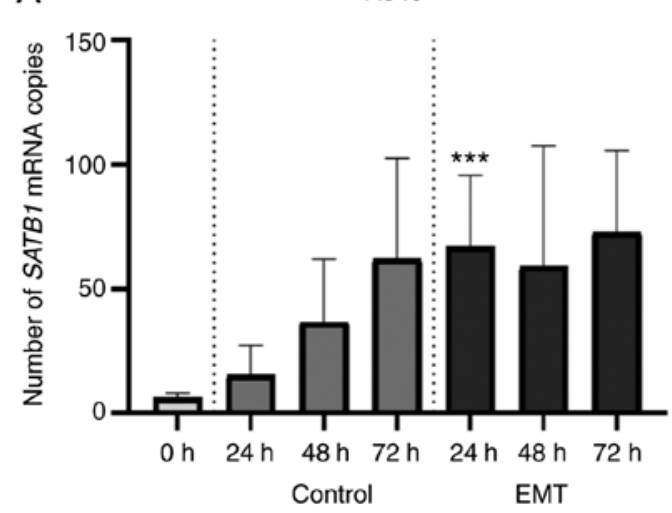

B

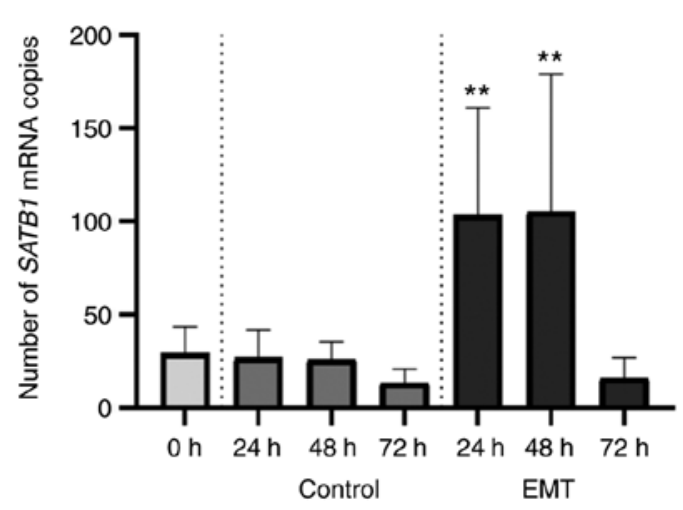

Figure 8. Changes in the expression of special AT-rich binding protein 1 (SATB1) mRNA after epithelial-mesenchymal transition (EMT) induction in the A549 and NCI-H1703 cell lines. (A) In the control A549 cells, SATB1 mRNA level gradually increased during the time of the culture, reaching its maximum value after $72 \mathrm{~h}$. While, $24 \mathrm{~h}$ after transforming growth factor (TGF)- $\beta 1$ exposure, SATB1 expression in EMT cells significantly increased compared to the control group. At $48 \mathrm{~h}$ after EMT induction, the $S A T B 1 \mathrm{mRNA}$ level was still slightly elevated, but not significantly different from the control. After $72 \mathrm{~h}$, SATB1 expression in EMT cells decreased to a control level. (B) Untreated NCI-H1703 cells showed a rather low SATB1 mRNA level, which remained stable during the $72 \mathrm{~h}$ of culture. Yet, $24 \mathrm{~h}$ after EMT induction, we observed a sharp increase in SATB1 expression that lasted for about $48 \mathrm{~h}$ after TGF- $\beta 1$ treatment. At 24 and $48 \mathrm{~h}$ after TGF- $\beta 1$ administration, $S A T B 1 \mathrm{mRNA}$ levels were significantly elevated compared to the control. Yet, $72 \mathrm{~h}$ after EMT induction, SATB1 expression dropped to a level comparable to the control cells at $72 \mathrm{~h}$. ${ }^{* *} \mathrm{P}<0.01$ and ${ }^{* * *} \mathrm{P}<0.001$. Error bars stand for standard deviation.

Twenty hours after TGF- $\beta 1$ exposre, SATB1 expression in EMT cells significantly increased compared to the control ones $(67.11 \pm 28.60$ vs. $15.36 \pm 11.79 ; \mathrm{P}=0.0001$; Fig. $8 \mathrm{~A})$. Forty-eight hours after the EMT induction, SATB1 mRNA level was still slightly elevated, but not significantly different from the control $(59.11 \pm 48.51$ vs. 36.67 \pm 25.22 ; ns; Fig. 8A). After $72 \mathrm{~h}, S A T B 1$ expression in EMT cells decreased to a control level (72.67 \pm 32.95 mRNA copies/sample).

Untreated NCI-H1703 cells showed a rather low SATB1 mRNA level (no more than 30 mRNA copies/sample), which remained stable during the $72 \mathrm{~h}$ of culture. Yet, $24 \mathrm{~h}$ after the EMT induction, we observed a sharp increase in $S A T B 1$ expression that lasted for about $48 \mathrm{~h}$ after TGF- $\beta 1$ exposre; 24 and $48 \mathrm{~h}$ after TGF- $\beta 1$ administration, SATB1 mRNA levels were significantly elevated compared to the control (103.70 \pm 57.29 vs. $27.13 \pm 14.94$ after $24 \mathrm{~h} ; \mathrm{P}=0.0029$; $105.40 \pm 73.85$ vs. $26.13 \pm 9.48$ after 48 h; $\mathrm{P}=0.0098$; Fig. $8 \mathrm{~B}$ ). Yet, $72 \mathrm{~h}$ after EMT induction, SATB1 expression dropped to a level comparable to the control cells $(16.29 \pm 10.80 \mathrm{vs}$. 13.58 \pm 7.32; ns; Fig. 8B). 


\section{Discussion}

The epidermal-mesenchymal transition (EMT) process is commonly thought to be one of the main mechanisms underlying cancer metastasis by enabling cancer cells to acquire an invasive phenotype $(9,15,17)$. Although the complex network of molecular factors orchestrating EMT has been extensively studied over the past 20 years, there are still unanswered questions and challenging topics to be explored. In recent years, there has been a growing interest in special AT-rich binding protein 1 (SATB1), a potent transcriptional regulator whose role in EMT was confirmed, among others, in breast, colorectal, prostate and bladder cancers (65). In these neoplasms, SATB1 was demonstrated not only to be associated with a high tumour malignancy and a poor patient prognosis, but also to promote an invasive, mesenchymal phenotype of the cells (65). In cancer cell lines, it was found to stimulate the expression of key mesenchymal markers such as vimentin and $\mathrm{N}$-cadherin, as well as the most important EMT-associated transcription factors: SNAIL, SLUG, and Twist1 $(43,46,50,52,56)$. It was also demonstrated to act as a repressor of the expression of epithelial proteins, including claudin-1 and E-cadherin $(43,46,56)$. SATB1 depletion in aggressive, tumorigenic cancer cell lines was sufficient not only to decrease cell proliferation rates, invasiveness, and resistance to apoptosis, but also to restore their polarization and anchorage-dependent growth $(43,45,52-55,66-68)$. These reports suggest that, in specific conditions, SATB1 may function as a specific 'trigger' of the malignant phenotype, clearly contributing to EMT and cancer metastasis.

Unfortunately, little is known about the role of SATB1 in the progression of non-small cell lung cancer (NSCLC), which is one of the most common and malignant human cancers. Previous reports are ambiguous and indicate that the function of SATB1 in NSCLC is highly dependent on the tumour histology [adenocarcinoma (AC) vs. squamous cell carcinoma (LSCC)] (58-60). To date, the possible role of SATB1 in EMT has not been investigated in NSCLC. A recent study was the first to analyse the relationships between the expression of SATB1 and EMT-associated proteins (E-cadherin, $\mathrm{N}$-cadherin, SNAIL, SLUG, and Twist1) in NSCLC clinical samples. Moreover, it also investigated the impact of in vitro EMT induction in NSCLC cell cultures on SATB1 mRNA levels for the first time.

One of the main EMT hallmarks, usually observed at the very beginning of this process, is a decrease in the expression of E-cadherin, a calcium-dependent cell-adhesion molecule that is one of the key epithelial markers (69). E-cadherin mediates cell-to-cell junctions and interactions and prevents migration, therefore it is a known tumour suppressor protein $(69,70)$. The loss of its expression not only results in the disruption of cell-to-cell contacts, but it was also demonstrated to activate downstream transcriptional pathways, leading to invasion and metastasis $(71,72)$. In NSCLC, a decreased E-cadherin level was shown to be associated with poor tumour differentiation, the presence of lymph node metastasis, and an advanced stage of the disease (73-76). In our study, we observed E-cadherin expression in most of the analysed NSCLC samples. However, there was no relationship with the patient clinicopathological or survival data. This supports previous findings by
Grigoras et al and Myong et al, who assessed E-cadherin expression in NSCLC and were not able to observe any significant associations with the majority of the clinicopathological factors analysed or the patients' survival $(77,78)$. However, although there are some studies in which the prognostic significance of the loss of E-cadherin expression in NSCLC has not been proven yet (73,76-78), in the majority of the experiments, a decreased E-cadherin level was found to be a negative prognostic factor for NSCLC patients, something that has also been confirmed by meta-analyses $(75,79,80)$.

Another protein from the cadherin family, closely associated with EMT progression, is N-cadherin, a key mesenchymal marker necessary for cell migration $(69,70)$. While E-cadherin expression is being supressed during EMT, the N-cadherin level significantly increases in a process called 'a cadherin switch' $(69,70,81)$. Aberrant $\mathrm{N}$-cadherin expression has been observed in most of the epithelial-derived solid tumours, and it was shown to be a factor that influenced patient survival negatively and was related to a high tumour grade and the presence of lymph node metastasis $(81,82)$. In the current study, although $\mathrm{N}$-cadherin expression was only noted in $\sim 8 \%$ of the NSCLC samples analysed, it was significantly related to the more advanced stage of the disease-both in the whole study cohort and in the LSCC subtype analysed separately. An increased $\mathrm{N}$-cadherin level also seemed to be slightly associated with the LSCC histology and the presence of lymph node metastasis in LSCC tumours, but the results were on the verge of statistical significance ( $\mathrm{P}=0.07$, in both cases). Moreover, we observed that $\mathrm{N}$-cadherin expression in LSCC tumours was significantly correlated with a shorter overall survival of the patients. Our results share a number of similarities with the findings of Hui et al, who also observed elevated $\mathrm{N}$-cadherin scores in advanced stage tumours and the negative impact of N-cadherin expression on NSCLC patient prognosis (83). Analogous relationships were seen in nasopharyngeal and oral squamous cell carcinomas as well $(84,85)$.

The whole EMT process is controlled at the transcriptional and post-transcriptional level by numerous transcription factors, chromatin modifying enzymes, miRNAs and long non-coding RNAs (9-11). The most important transcription regulators coordinating the shift from epithelial to mesenchymal phenotype are SNAIL, SLUG, and Twist1 (9-11). These proteins are responsible for downregulating E-cadherin and activating traits leading to the upregulation of mesenchymal markers, additionally influencing apoptosis, angiogenesis, and cell migration (86-88). The overexpression of each of these transcription factors has been confirmed to have a negative prognostic significance in most common epithelial cancers (88-90). In our study, we observed an elevated SNAIL, SLUG, and Twist1 immunoreactivity in NSCLC compared to NMLT samples, which is in line with previous literature reports (91-93). However, some researchers noticed SNAIL staining in the nuclei of tumour cells $(86,94)$, while we only observed it in the cytoplasm. These differences may be due to the use of different IHC methodologies and antibodies. However, recent reports suggest that subcellular SNAIL localization may be one of the mechanisms to regulate its activity during EMT (95), so this issue surely needs to be investigated more thoroughly in the future. In this study, we did not note any difference in SNAIL staining between the particular NSCLC 
subtypes, which is consistent with Merikallio et al (86) and Yanagawa et al (91). In LSCC, elevated SNAIL scores were associated with the presence of lymph node metastases and an advanced stage of the disease, which fits the results obtained by Abd El-Rehim et al (94). Although some studies stated that elevated SNAIL scores are related to a shortened NSCLC patient survival $(86,91)$, in our research, SNAIL expression did not reach prognostic significance.

It is known that SLUG can promote lung cancer invasion and metastasis (96), but there are not many reports analysing its expression in NSCLC clinical samples. Therefore, it is challenging to discuss the results obtained in the current study. In 2014, Merikaillo et al investigated SLUG immunostaining in more than 250 NSCLC samples, but the only associations analysed were those with the histological subtype of the tumour and the patient survival (97). On the other hand, Hung et al analysed SLUG expression in 85 NSCLC tumours, but they did not observe any associations with the patient clinicopathological data (98). In our study, nuclear SLUG staining was significantly associated with the LSCC histology, whereas staining in the cytoplasm of the tumour cells did not differ among particular NSCLC subtypes, which is in good agreement with Merikallio et al (97). In LSCC, both nuclear and cytoplasmic SLUG expression was positively associated with the size of the tumour and the stage of the disease. In AC, an elevated cytoplasmic SLUG staining was related to a poor degree of tumour differentiation. In contrast to Jiang et al (93) and Merikallio et al (97), we did not observe any impact of SLUG expression on patient survival.

We observed Twist1 expression predominantly in LSCC tumours, which is consistent with Jiang et al (93). Additionally, its elevated scores were related to a more advanced stage of the disease, which supports the results obtained by Hui et al (83). However, a meta-analysis of 5 different studies regarding Twistl expression in NSCLC did not confirm these findings, revealing that in the experiments analysed, Twistl overexpression was associated only with the presence of lymph node metastasis (99). We did not find Twist1 expression to be prognostically significant in the NSCLC samples analysed. Although the meta-analyses (based mainly on Chinese population studies) stated that Twist1 overexpression was a negative prognostic factor $(99,100)$ in NSCLC, there are also several studies that lend support to our findings $(83,101)$.

The association between SATB1 level and the expression of various EMT-associated factors has been revealed, to date, in breast, colorectal, prostate, liver, and bladder cancers $(43,45,46,52,55,56)$. Nevertheless, these studies were mostly based on the loss-of-function cell culture models and did not analyse the potential link between the expression of SATB1 and the EMT-promoting factors in clinical material. It is known that SATB1 immunostaining is correlated with the expression of vimentin and negatively correlated with the expression of E-cadherin and CK20 in colorectal cancer clinical samples (51), but no reports concerning lung carcinomas are available. Therefore, we are the first researchers to investigate the relationship between the expression of SATB1 and EMT-associated proteins in NSCLC tumours. We found SNAIL, SLUG, and Twist1 expression levels to be positively correlated with SATB1 scores in the whole study cohort, which clearly indicates a possible association between SATB1 expression and the progression of EMT in these tumours. Moreover, nuclear and cytoplasmic SLUG staining was positively correlated with the expression of SATB1 in particular NSCLC subtypes as well. Surprisingly, the associations were the strongest in LSCC samples, which seems to be contradictory with the positive prognostic significance of SATB1 expression in these tumours observed by Selinger et al (58). However, in our current and recent studies, we have not noted a statistically significant link between either SATB1 or SLUG expression and LSCC patient survival (59). In the currently analysed material, we also observed a positive correlation between SATB1 and Twist1 expressions in AC samples, which is consistent with the postulated tumour-promoting role of these two factors in adenocarcinomas $(60,102)$.

Although SATB1 has been shown to have an impact on E-cadherin and $\mathrm{N}$-cadherin expressions in numerous cancer cell lines $(43,45,46,52,55,56)$, we did not note any relationship among the levels of these factors in NSCLC clinical samples. Instead, surprisingly, we observed a significant positive correlation between E-cadherin expression and the Ki-67 proliferative index, both in the whole study cohort and in the AC subtype alone. Similar associations have been reported in laryngeal and endometrial cancers $(103,104)$, but not in NSCLC. N-cadherin, SNAIL, SLUG, and Twist1 scores were also positively correlated with the Ki-67 proliferative index, which seems to be consistent with their tumour-promoting function.

It has been revealed in several studies that ectopic SATB1 overexpression is enough to induce EMT-like changes in cancer cells. However, there are no described experiments in which the reverse relationship would be studied (the impact of EMT on SATB1 level). We were the first ones to investigate whether the induction of EMT in cultured NSCLC cells affects the expression of $S A T B 1$ somehow. We revealed that the $S A T B 1$ mRNA level significantly increased after TGF- $\beta 1$ exposure, both in the A549 (AC) and the NCI-H1703 (LSCC) cell lines. These changes in SATB1 expression were accompanied by a visible morphological shift from an epithelial to a mesenchymal phenotype, together with a significant increase in the expression of genes coding for $\mathrm{N}$-cadherin and EMT-promoting transcription factors ( $C D H 2, S N A I 1$, and $S N A I 2$, respectively). These results may indicate the role of SATB1 as an EMT-inducer in NSCLC.

In conclusion, SATB1 is a known tumour-promoting factor whose negative prognostic significance has been observed in numerous cancers. It has been shown to be associated with an invasive tumour phenotype and to promote metastatic spread. In recent years, an increasing number of reports have also pointed to a possible role of SATB1 as an EMT-promoting factor. Links between SATB1 expression and the progression of EMT have been noticed in several epithelial cancers, including those of the breast, colon, liver, prostate, and bladder. However, non-small cell lung carcinomas, the most abundant lung cancer subtype, have never be analysed in the context of SATB1/EMT associations. We were the first to analyse the relationship between the expression of SATB1 and key EMT-associated proteins (E-cadherin, N-cadherin, SNAIL, SLUG, and Twist1) in NSCLC clinical samples. Additionally, we also investigated the impact of EMT induction in NSCLC cell lines on the expression of SATB1 mRNA. We observed significant positive correlations between the expression of 
SATB1 and the most crucial EMT-promoting transcription factors: SNAIL, SLUG, and Twist1. We also showed that SATB1 expression significantly increased after in vitro EMT induction in the A549 and the NCI-H1703 NSCLC cell lines. These results may indicate the role of SATB1 as one of the positive EMT regulators in NSCLC.

\section{Acknowledgements}

Not applicable.

\section{Funding}

This study was funded by a grant from the Medical University in Wroclaw, Poland (no. STM.A110.17.023).

\section{Availability of data and materials}

The datasets analyzed during the current study are available from the corresponding author on reasonable request.

\section{Authors' contributions}

Conceptualization of the research study was achieved by NGP and PD. Formal analysis was conducted by NGP. Funding acquisition was by NGP. Investigation and experimentation was performed by NGP and AP. Methodology was designed by NGP and AP. Resources were the responsibility of AR and supervision was conducted by MPO and PD. Visualization was performed by NGP. Writing of the original draft was performed by NGP and writing, review and editing was conducted by AR, MPO and PD. All authors read and approved the manuscript and agree to be accountable for all aspects of the research in ensuring that the accuracy or integrity of any part of the work are appropriately investigated and resolved.

\section{Ethics approval and consent to participate}

The present study was approved by the Bioethics Commission at the Wroclaw Medical University in Poland (approval no. KB-632/2017). The present study was conducted on archival clinical material only, thus no patient consent was needed.

\section{Patient consent for publication}

Not applicable.

\section{Competing interests}

The authors declare that they have no competing interests.

\section{References}

1. Ferlay J, Ervik M, Lam F, Colombet M, Mery L, Piñeros M, Znaor A, Soerjomataram I and Bray F (eds.): Global Cancer Observatory: Cancer Today. Int Agency Res Cancer, 2018. https:// publications.iarc.fr/Databases/Iarc-Cancerbases/Cancer-TodayPowered-By-GLOBOCAN-2018--2018. Accessed, December 6 2019-12-06.

2. Zappa $\mathrm{C}$ and Mousa SA: Non-small cell lung cancer: Current treatment and future advances. Transl Lung Cancer Res 5: 288-300, 2016.
3. Travis WD, Brambilla E, Burke AP, Marx A and Nicholson AG: Introduction to The 2015 World Health Organization Classification of tumours of the lung, pleura, thymus and heart. J Thorac Oncol 10: 1240-1242, 2015.

4. Perlikos F, Harrington KJ and Syrigos KN: Key molecular mechanisms in lung cancer invasion and metastasis: A comprehensive review. Crit Rev Oncol Hematol 87: 1-11, 2013.

5. Tamura T, Kurishima K, Nakazawa K, Kagahashi K, Ishikawa $H$, Satoh $\mathrm{H}$ and Hizawa N: Specific organ metastases and survival in metastatic non-small-cell lung cancer. Mol Clin Oncol 3: 217-221, 2015.

6. Milovanovic IS, Stjepanovic M and Mitrovic D: Distribution patterns of the metastases of the lung carcinoma in relation to histological type of the primary tumor: An autopsy study. Ann Thorac Med 12: 191-198, 2017.

7. Hsu F, De Caluwe A, Anderson D, Nichol A, Toriumi T and Ho C: Patterns of spread and prognostic implications of lung cancer metastasis in an era of driver mutations. Curr Oncol 24: 228-233, 2017.

8. Howlader N, Noone AM, Krapcho M, Miller D, Brest A, Yu M, Ruhl J, Tatalovich Z, Mariotto A, Lewis DR, et al: SEER Cancer Statistics Review, 1975-2017. https://seer.cancer.gov/ csr/1975_2017. Accessed, April 15, 2020.

9. Diepenbruck M and Christofori G: Epithelial-mesenchymal transition (EMT) and metastasis: Yes, no, maybe? Curr Opin Cell Biol 43: 7-13, 2016.

10. Yang $X$, Liang $X$, Zheng $M$ and Tang $Y$ : Cellular phenotype plasticity in cancer dormancy and metastasis. Front Oncol 8: 505, 2018

11. De Craene B and Berx G: Regulatory networks defining EMT during cancer initiation and progression. Nat Rev Cancer 13: 97-110, 2013.

12. Zhang Y and Weinberg RA: Epithelial-to-mesenchymal transition in cancer: Complexity and opportunities. Front Med 12: 361-373, 2018.

13. Santamaria PG, Moreno-Bueno G, Portillo F and Cano A: EMT: Present and future in clinical oncology. Mol Oncol 11: 718-738, 2017.

14. Singh M, Yelle N, Venugopal C and Singh SK: EMT: Mechanisms and therapeutic implications. Pharmacol Ther 182: 80-94, 2018.

15. Pastushenko I and Blanpain C: EMT transition states during tumor progression and metastasis. Trends Cell Biol 29: 212-226, 2019.

16. Frixen UH, Behrens J, Sachs M, Eberle G, Voss B, Warda A, Löchner D and Birchmeier W: E-cadherin-mediated cell-cell adhesion prevents invasiveness of human carcinoma cells. J Cell Biol 113: 173-185, 1991.

17. Thiery JP: Epithelial-mesenchymal transitions in tumour progression. Nat Rev Cancer 2: 442-454, 2002.

18. Nagathihalli NS, Massion PP, Gonzalez AL, Lu P and Datta PK: Smoking induces epithelial-to-mesenchymal transition in non-small cell lung cancer through HDAC-mediated downregulation of E-cadherin. Mol Cancer Ther 11: 2362-2372, 2012.

19. Mahmood MQ, Walters EH, Shukla SD, Weston S, Muller HK, Ward C and Sohal SS: $\beta$-catenin, Twist and Snail: Transcriptional regulation of EMT in smokers and COPD, and relation to airflow obstruction. Sci Rep 7: 10832, 2017.

20. Zhu X, Chen L, Liu L and Niu X: EMT-Mediated Acquired EGFR-TKI resistance in NSCLC: Mechanisms and strategies. Front Oncol 9: 1044, 2019.

21. Tulchinsky E, Demidov O, Kriajevska M, Barlev NA and Imyanitov E: EMT: A mechanism for escape from EGFR-targeted therapy in lung cancer. Biochim Biophys Acta Rev Cancer 1871: 29-39, 2019.

22. Bronte G, Bravaccini S, Bronte E, Burgio MA, Rolfo C, Delmonte A and Crinò L: Epithelial-to-mesenchymal transition in the context of epidermal growth factor receptor inhibition in non-small-cell lung cancer. Biol Rev Camb Philos Soc 93: 1735-1746, 2018.

23. Li M, Yang J, Zhou W, Ren Y, Wang X, Chen H, Zhang J, Chen J, Sun Y, Cui L, et al: Activation of an AKT/FOXM1/STMN1 pathway drives resistance to tyrosine kinase inhibitors in lung cancer. Br J Cancer 117: 974-983, 2017.

24. Santamaría PG, Moreno-Bueno G and Cano A: Contribution of epithelial plasticity to therapy resistance. J Clin Med 8: 676, 2019.

25. Liang SQ, Marti TM, Dorn P, Froment L, Hall SR, Berezowska S, Kocher G, Schmid RA and Peng RW: Blocking the epithelial-to-mesenchymal transition pathway abrogates resistance to anti-folate chemotherapy in lung cancer. Cell Death Dis 6: e1824, 2015.

26. Zheng HC: The molecular mechanisms of chemoresistance in cancers. Oncotarget 8: 59950-59964, 2017. 
27. Fischer KR, Durrans A, Lee S, Sheng J, Li F, Wong ST, Choi H, El Rayes T, Ryu S, Troeger J, et al: Epithelial-to-mesenchymal transition is not required for lung metastasis but contributes to chemoresistance. Nature 527: 472-476, 2015.

28. Kohwi-Shigematsu T, Kohwi Y, Takahashi K, Richards HW, Ayers SD, Han HJ and Cai S: SATB1-mediated functional packaging of chromatin into loops. Methods 58: 243-254, 2012.

29. Galande S, Purbey PK, Notani D and Kumar PP: The third dimension of gene regulation: Organization of dynamic chromatin loopscape by SATB1. Curr Opin Genet Dev 17: 408-414, 2007.

30. Kohwi-Shigematsu T, Poterlowicz K, Ordinario E, Han HJ, Botchkarev VA and Kohwi Y: Genome organizing function of SATB1 in tumor progression. Semin Cancer Biol 23: 72-79, 2013

31. Fessing MY, Mardaryev AN, Gdula MR, Sharov AA, Sharova TY, Rapisarda V, Gordon KB, Smorodchenko AD, Poterlowicz K, Ferone G, et al: p63 regulates Satb1 to control tissue-specific chromatin remodeling during development of the epidermis. J Cell Biol 194: 825-839, 2011.

32. Pavan Kumar P, Purbey PK, Sinha CK, Notani D, Limaye A, Jayani RS and Galande S: Phosphorylation of SATB1, a global gene regulator, acts as a molecular switch regulating its transcriptional activity in vivo. Mol Cell 22: 231-243, 2006.

33. Purbey PK, Singh S, Notani D, Kumar PP, Limaye AS and Galande S: Acetylation-dependent interaction of SATB1 and CtBP1 mediates transcriptional repression by SATB1. Mol Cell Biol 29: 1321-1337, 2009.

34. Nagpal N, Ahmad HM, Molparia B and Kulshreshtha R: MicroRNA-191, an estrogen-responsive microRNA, functions as an oncogenic regulator in human breast cancer. Carcinogenesis 34: 1889-1899, 2013

35. Brown CY, Dayan S, Wong SW, Kaczmarek A, Hope CM, Pederson SM, Arnet V, Goodall GJ, Russell D, Sadlon TJ and Barry SC: FOXP3 and miR-155 cooperate to control the invasive potential of human breast cancer cells by down regulating ZEB2 independently of ZEB1. Oncotarget 9: 27708-27727, 2018.

36. Li QQ, Chen ZQ, Cao XX, Xu JD, Xu JW, Chen YY, Wang WJ, Chen Q, Tang F, Liu XP and Xu ZD: Involvement of $\mathrm{NF}-\kappa \mathrm{B} / \mathrm{miR}-448$ regulatory feedback loop in chemotherapy-induced epithelial-mesenchymal transition of breast cancer cells. Cell Death Differ 18: 16-25, 2011.

37. McInnes N, Sadlon TJ, Brown CY, Pederson S, Beyer M, Schultze JL, McColl S, Goodall GJ and Barry SC: FOXP3 and FOXP3-regulated microRNAs suppress SATB1 in breast cancer cells. Oncogene 31: 1045-1054, 2012.

38. Pan X, Li D, Huo J, Kong F, Yang H and Ma X: LINC01016 promotes the malignant phenotype of endometrial cancer cells by regulating the miR-302a-3p/miR-3130-3p/NFYA/SATB1 axis. Cell Death Dis 9: 303, 2018.

39. Lopes-Ramos CM, Habr-Gama A, Quevedo Bde S, Felício NM, Bettoni F, Koyama FC, Asprino PF, Galante PA, Gama-Rodrigues J, Camargo AA, et al: Overexpression of miR-21-5p as a predictive marker for complete tumor regression to neoadjuvant chemoradiotherapy in rectal cancer patients BMC Med Genomics 7: 68, 2014.

40. Kowalczyk AE, Krazinski BE, Godlewski J, Grzegrzolka J, Kiewisz J, Kwiatkowski P, Sliwinska-Jewsiewicka A, Dziegiel P and Kmiec Z: SATB1 is Down-regulated in clear cell renal cell carcinoma and correlates with miR-21-5p overexpression and poor prognosis. Cancer Genomics Proteomics 13: 209-217, 2016.

41. Alvarez JD, Yasui DH, Niida H, Joh T, Loh DY and Kohwi-Shigematsu T: The MAR-binding protein SATB1 orchestrates temporal and spatial expression of multiple genes during T-cell development. Genes Dev 14: 521-535, 2000.

42. Savarese F, Dávila A, Nechanitzky R, De La Rosa-Velazquez I, Pereira CF, Engelke R, Takahashi K, Jenuwein $T$, Kohwi-Shigematsu T, Fisher AG and Grosschedl R: Satb1 and Satb2 regulate embryonic stem cell differentiation and Nanog expression. Genes Dev 23: 2625-2638, 2009.

43. Han HJ, Russo J, Kohwi Y and Kohwi-Shigematsu T: SATB1 reprogrammes gene expression to promote breast tumour growth and metastasis. Nature 452: 187-193, 2008.

44. Nodin B, Johannesson H, Wangefjord S, O'Connor DP, Lindquist KE, Uhlén M, Jirström K and Eberhard J: Molecular correlates and prognostic significance of SATB1 expression in colorectal cancer. Diagn Pathol 7: 115, 2012.

45. Shukla S, Sharma H, Abbas A, MacLennan GT, Fu P, Danielpour D and Gupta S: Upregulation of SATB1 is associated with prostate cancer aggressiveness and disease progression. PLoS One 8: e53527, 2013
46. Tu W, Luo M, Wang Z, Yan W, Xia Y, Deng H, He J, Han P and Tian D: Upregulation of SATB1 promotes tumor growth and metastasis in liver cancer. Liver Int 32: 1064-1078, 2012.

47. Han B, Luan L, Xu Z and Wu B: Expression and biological roles of SATB1 in human bladder cancer. Tumor Biol 34: 2943-2949, 2013.

48. Nodin B, Hedner C, Uhlén M and Jirström K: Expression of the global regulator SATB1 is an independent factor of poor prognosis in high grade epithelial ovarian cancer. J Ovarian Res 5: 24,2012 .

49. Wang S, Zeng J, Xiao R, Xu G, Liu G, Xiong D, Ye Y, Chen B, Wang H, Luo Q and Huang Z: Poor prognosis and SATB1 overexpression in solid tumors: A meta-analysis. Cancer Manag Res 10: 1471-1478, 2018

50. Sun Z, Zhang C, Zou X, Jiang G, Xu Z, Li W and Xie H: Special AT-rich sequence-binding protein-1 participates in the maintenance of breast cancer stem cells through regulation of the Notch signaling pathway and expression of Snaill and Twist1. Mol Med Rep 11: 3235-3242, 2015.

51. Lv JH, Wang F, Shen MH, Wang X and Zhou XJ: SATB1 expression is correlated with $\beta$-catenin associated epithelial-mesenchymal transition in colorectal cancer. Cancer Biol Ther 17: 254-261, 2016.

52. Frömberg A, Rabe $M$ and Aigner A: Multiple effects of the special AT-rich binding protein 1 (SATB1) in colon carcinoma. Int J Cancer 135: 2537-2546, 2014.

53. Mao L, Yang C, Wang J, Li W, Wen R, Chen J and Zheng J: SATB1 is overexpressed in metastatic prostate cancer and promotes prostate cancer cell growth and invasion. J Transl Med 11: 111, 2013

54. Mao LJ, Zhang J, Liu N, Fan L, Yang DR, Xue BX, Shan YX and Zheng JN: Oncolytic virus carrying shRNA targeting SATB1 inhibits prostate cancer growth and metastasis. Tumor Biol 36 9073-9081, 2015.

55. Qi H, Fu X, Li Y, Pang X, Chen S, Zhu X, Li F and Tan W: SATB1 promotes epithelial-mesenchymal transition and metastasis in prostate cancer. Oncol Lett 13: 2577-2582, 2017.

56. Wan F, Cheng C, Wang Z, Xiao X, Zeng H, Xing S, Chen X, Wang J, Li S, Zhang Y, et al: SATB1 overexpression regulates the development and progression in bladder cancer through EMT. PLoS One 10: e0117518, 2015.

57. Baguma-Nibasheka M, Angka HE, Inanlou MR and Kablar B: Microarray analysis of Myf5 $5^{-/}: \mathrm{MyoD}^{-/}$hypoplastic mouse lungs reveals a profile of genes involved in pneumocyte differentiation. Histol Histopathol 22: 483-495, 2007.

58. Selinger CI, Cooper WA, Al-Sohaily S, Mladenova DN Pangon L, Kennedy CW, McCaughan BC, Stirzaker C and Kohonen-Corish MR: Loss of special AT-rich binding protein 1 expression is a marker of poor survival in lung cancer. J Thorac Oncol 6: 1179-1189, 2011

59. Glatzel-Plucinska N, Piotrowska A, Grzegrzolka J, Olbromski M, Rzechonek A, Dziegiel P and Podhorska-Okolow M: SATB1 level correlates with $\mathrm{Ki}-67$ expression and is a positive prognostic factor in non-small cell lung carcinoma. Anticancer Res 38: 723-736, 2018 .

60. Huang B, Zhou H, Wang S, Lang XP and Wang X: Effect of silencing SATB1 on proliferation, invasion and apoptosis of A549 human lung adenocarcinoma cells. Oncol Lett 12: 3818-3824, 2016.

61. Huang B, Zhou H, Wang X and Liu Z: Silencing SATB1 with siRNA inhibits the proliferation and invasion of small cell lung cancer cells. Cancer Cell Int 13: 8, 2013

62. Detterbeck FC, Boffa DJ and Tanoue LT: The new lung cancer staging system. Chest 136: 260-271, 2009.

63. Tuffaha MSA: Phenotypic and Genotypic Diagnosis of Malignancies: An Immunohistochemical and Molecular Approach. 1st edition. Wiley-VCH, 2008.

64. Mogilner A and Keren K: The shape of motile cells. Curr Biol 19: R762-R771, 2009.

65. Glatzel-Plucinska N, Piotrowska A, Dziegiel $\mathrm{P}$ and Podhorska-Okołów M: The role of SATB1 in tumour progression and metastasis. Int J Mol Sci 20: 4156, 2019.

66. Zhang J, Zhang B, Zhang X, Sun Y, Wei X, McNutt MA, Lu S, Liu Y, Zhang D, Wang M, et al: SATB1 expression is associated with biologic behavior in colorectal carcinoma in vitro and in vivo. PLoS One 8: e47902, 2013.

67. Mansour MA, Hyodo T, Akter KA, Kokuryo T, Uehara K, Nagino $M$ and Senga T: SATB1 and SATB2 play opposing roles in c-Myc expression and progression of colorectal cancer. Oncotarget 7: 4993-5006, 2016. 
68. Zhang Y, Tian X, Ji H, Guan X, Xu W, Dong B, Zhao M, Wei M Ye C, Sun Y, et al: Expression of SATB1 promotes the growth and metastasis of colorectal cancer. PLoS One 9: e100413, 2014.

69. Loh CY, Chai JY, Tang TF, Wong WF, Sethi G, Shanmugam MK, Chong PP and Looi CY: The E-Cadherin and N-Cadherin switch in epithelial-to-mesenchymal transition: Signaling, therapeutic implications, and challenges. Cells 8: 1118, 2019.

70. Berx G and van Roy F: Involvement of members of the cadherin superfamily in cancer. Cold Spring Harb Perspect Biol 1: a003129, 2009.

71. Bae GY, Choi SJ, Lee JS, Jo J, Lee J, Kim J and Cha HJ: Loss of E-cadherin activates EGFR-MEK/ERK signaling, which promotes invasion via the ZEB1/MMP2 axis in non-small cell lung cancer. Oncotarget 4: 2512-2522, 2013.

72. Onder TT, Gupta PB, Mani SA, Yang J, Lander ES and Weinberg RA: Loss of E-Cadherin promotes metastasis via multiple downstream transcriptional pathways. Cancer Res 68 : 3645-3654, 2008.

73. Kase S, Sugio K, Yamazaki K, Okamoto T, Yano T and Sugimachi K: Expression of E-cadherin and beta-catenin in human non-small cell lung cancer and the clinical significance. Clin Cancer Res 6: 4789-4796, 2000.

74. Bremnes RM, Veve R, Gabrielson E, Hirsch FR, Baron A, Bemis L, Gemmill RM, Drabkin HA and Franklin WA: High-throughput tissue microarray analysis used to evaluate biology and prognostic significance of the E-cadherin pathway in non-small-cell lung cancer. J Clin Oncol 20: 2417-2428, 2002.

75. Yan B, Zhang W, Jiang LY, Qin WX and Wang X: Reduced E-Cadherin expression is a prognostic biomarker of non-small cell lung cancer: A meta-analysis based on 2395 subjects. Int J Clin Exp Med 7: 4352-4356, 2014.

76. Lee YC, Wu CT, Chen CS and Chang YL: E-Cadherin expression in surgically-resected non-small cell lung cancers-A clinicopathological study. Thorac Cardiovasc Surg 48: 294-299, 2000.

77. Grigoras ML, Arghirescu TS, Folescu R, Talpoș IC, Gîndac CM, Zamfir CL, Cornianu M, Anghel MD and Levai CM: Expression of E-cadherin in lung carcinoma, other than those with small cells (NSCLC). Rom J Morphol Embryol 58: 1317-1325, 2017.

78. Myong NH: Reduced expression of E-cadherin in human non-small cell lung carcinoma. Cancer Res Treat 36: 56-61, 2004

79. Wu Y, Liu HB, Ding M, Liu JN, Zhan P, Fu XS and Lu G: The impact of E-cadherin expression on non-small cell lung cance survival: A meta-analysis. Mol Biol Rep 39: 9621-9628, 2012.

80. Yang YL, Chen MW and Xian L: Prognostic and clinicopathological significance of downregulated E-cadherin expression in patients with non-small cell lung cancer (NSCLC): A metaanalysis. PLoS One 9: e99763, 2014.

81. Mrozik KM, Blaschuk OW, Cheong CM, Zannettino ACW and Vandyke $\mathrm{K}$ : N-cadherin in cancer metastasis, its emerging role in haematological malignancies and potential as a therapeutic target in cancer. BMC Cancer 18: 939, 2018.

82. Luo Y, Yu T, Zhang Q, Fu Q, Hu Y, Xiang M, Peng H, Zheng T, $\mathrm{Lu} \mathrm{L}$ and Shi $\mathrm{H}$ : Upregulated $\mathrm{N}$-cadherin expression is associated with poor prognosis in epithelial-derived solid tumours: A meta-analysis. Eur J Clin Invest 48: e12903, 2018.

83. Hui L, Zhang S, Dong X, Tian D, Cui Z and Qiu X: Prognostic significance of twist and N-cadherin expression in NSCLC. PLoS One 8: e62171, 2013.

84. Sun H, Liu M, Wu X, Yang C, Zhang Y, Xu Z, Gao K and Wang F: Overexpression of $\mathrm{N}$-cadherin and $\beta$-catenin correlates with poor prognosis in patients with nasopharyngeal carcinoma. Oncol Lett 13: 1725-1730, 2017.

85. Ozaki-Honda Y, Seki S, Fujiwara M, Matsuura M, Fujita S Ikeda H, Umeda M, Ayuse T and Ikeda T: Prognostic prediction of oral squamous cell carcinoma by E-Cadherin and N-Cadherin expression in overall cells in tumor nests or tumor cells at the invasive front. Cancer Microenviron 10: 87-94, 2017.

86. Merikallio H, Turpeenniemi-Hujanen T, Pääkkö P, Mäkitaro R, Riitta K, Salo S, Salo T, Harju T and Soini Y: Snail promotes an invasive phenotype in lung carcinoma. Respir Res 13: 104, 2012
87. Alves CC, Carneiro F, Hoefler H and Becker KF: Role of the epithelial-mesenchymal transition regulator Slug in primary human cancers. Front Biosci (Landmark Ed) 14: 3035-3050, 2009.

88. Zhao Z, Rahman MA, Chen ZG and Shin DM: Multiple biological functions of Twist1 in various cancers. Oncotarget 8 . 20380-20393, 2017.

89. Zhang P, Hu P, Shen H, Yu J, Liu Q and Du J: Prognostic role of Twist or Snail in various carcinomas: A systematic review and meta-analysis. Eur J Clin Invest 44: 1072-1094, 2014.

90. Huang C, Zhang P, Zhang D and Weng X: The prognostic implication of slug in all tumour patients-a systematic meta-analysis. Eur J Clin Invest 46: 398-407, 2016.

91. Yanagawa J, Walser TC, Zhu LX, Hong L, Fishbein MC, Mah V, Chia D, Goodglick L, Elashoff DA, Luo J, et al: Snail promotes CXCR2 ligand-dependent tumor progression in non-small cell lung carcinoma. Clin Cancer Res 15: 6820-6829, 2009.

92.Liu CW, Li CH, Peng YJ, Cheng YW, Chen HW, Liao PL, Kang JJ and Yeng MH: Snail regulates Nanog status during the epithelial-mesenchymal transition via the Smad1/Akt/GSK3 $\beta$ signaling pathway in non-small-cell lung cancer. Oncotarget 5: 3880-3894, 2014

93. Jiang W, Pang XG, Wang Q, Shen YX, Chen XK and Xi JJ: Prognostic role of Twist, Slug, and Foxc2 expression in stage $\mathrm{i}$ non-small-cell lung cancer after curative resection. Clin Lung Cancer 13: 280-287, 2012.

94. Abd El-Rehim DM, Abd-Elghany MI and Nazmy MH Integrin-Linked kinase, Snail and multidrug resistance protein 1 Three concordant players in the progression of non-small cell lung cancer. J Egypt Natl Canc Inst 27: 129-137, 2015.

95. Muqbil I, Wu J, Aboukameel A, Mohammad RM and Azmi AS: Snail nuclear transport: The gateways regulating epithelial-to-mesenchymal transition? Semin Cancer Biol 27 39-45, 2014.

96. Shih JY and Yang PC: The EMT regulator slug and lung carcinogenesis. Carcinogenesis 32: 1299-1304, 2011.

97. Merikallio H, Turpeenniemi-Hujanen TT, Pääkkö P, Mäkitaro R Kaarteenaho R, Lehtonen S, Salo S, Salo T, Harju T and Soini Y: Slug is associated with poor survival in squamous cell carcinoma of the lung. Int J Clin Exp Pathol 7: 5846-5854, 2014

98. Hung PF, Hong TM, Chang CC, Hung CL, Hsu YL, Chang YL, Wu CT, Chang GC, Chan NL, Yu SL, et al: Hypoxia-induced Slug SUMOylation enhances lung cancer metastasis. J Exp Clin Cancer Res 38: 5, 2019.

99. Li M, Zhang X, Xu X, Wu J, Hu K, Guo X and Zhang P Clinicopathological and prognostic significance of Twist overexpression in NSCLC. Oncotarget 9: 14642-14651, 2018.

100. Zeng J, Zhan P, Wu G, Yang W, Liang W, Lv T and Song Y: Prognostic value of twist in lung cancer: Systematic review and meta-analysis. Transl Lung Cancer Res 4: 236-241, 2015.

101. Shi Y, Wu H, Zhang M, Ding L, Meng F and Fan X: Expression of the epithelial-mesenchymal transition-related proteins and their clinical significance in lung adenocarcinoma. Diagn Pathol 8: 89, 2013

102. Pallier K, Cessot A, Côté JF, Just PA, Cazes A, Fabre E, Danel C, Riquet M, Devouassoux-Shisheboran M, Ansieau S, et al TWIST1 a new determinant of epithelial to mesenchymal transition in EGFR mutated lung adenocarcinoma. PLoS One 7: e29954, 2012.

103. Barutçu O, Kara M, Muratlı A, Güçlü O and Dereköy S: Clinical significance of $\mathrm{Ki}-67$, c-erbB-2 and E-cadherin expressions in open partial laryngectomy patients. Kulak Burun Bogaz Ihtis Derg 26: 283-292, 2016.

104. González-Rodilla I, Aller L, Llorca J, Muñoz AB, Verna V, Estévez J and Schneider J: The E-Cadherin expression vs. tumor cell proliferation paradox in endometrial cancer. Anticancer Res 33: 5091-5095, 2013

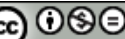

This work is licensed under a Creative Commons Attribution-NonCommercial-NoDerivatives 4.0 International (CC BY-NC-ND 4.0) License. 